\title{
Tragicomedia de Calisto y Melibea: testimonios recuperados y una nueva edición [Roma, Marcelo Silber, 1512-1515]
}

\author{
M. ${ }^{a}$ Jesús Lacarra \& Ana Milagros Jiménez Ruiz \\ Universidad de Zaragoza - Instituto de Patrimonio y Humanidades
}

\section{RESUMEN}

En el trabajo se repasan los recientes hallazgos de nuevas ediciones, o ejemplares no documentados, de la Tragicomedia de Calisto y Melibea. También se da a conocer un curioso testimonio manipulado, conservado en la Biblioteca estatal de Ulm, que transmite, junto a las dos primeras hojas de Valencia (Juan Jofré, 1514), una edición desconocida hasta la fecha que incorpora el éxplicit rimado con la particular contrahechura «Sevilla 1502». Un análisis tipobiblioiconográfico y de ecdótica textual e iconográfica nos lleva a identificarla como [Roma: Marcelo Silber: 1512-1515].

Palabras Clave: Tragicomedia de Calisto y Melibea, nueva edición, Silber, Roma [1512-1515], Sevilla, 1502.

\section{Tragicomedia de Calisto y Melibea: recovered testimonies and a new edition: [Rome, Marcellus Silber, 1512-1515]}

\begin{abstract}
The article reviews the recent findings of new editions, or undocumented copies, of the Tragicomedia de Calisto y Melibea. An interesting manipulated testimony, preserved at the Ulm City Library, is presented. This copy includes a testimony of two Valence-1514-edition folios and an unknown edition with the particular éxplicit that includes the fake place and date «Seville 1502». After a bibliographical, textual and material-iconographic analysis, we consider this new edition as [Rome: Marcellus Silber: 1512-1515].
\end{abstract}

Key words: Tragicomedia de Calisto y Melibea, new edition, Silber, Rome [15121515], Seville, 1502 


\section{Descubrimientos recientes de nuevas Celestinas ${ }^{1}$}

Celestina, conocida inicialmente como Comedia de Calisto y Melibea en su versión en 16 actos y posteriormente en su versión ampliada a 21, como Tragicomedia de Calisto y Melibea, gozó de un éxito excepcional en las prensas, solo parangonable con el Quijote en el terreno de la ficción. Siguiendo unos criterios muy restrictivos, que comportan limitarnos únicamente a aquellas ediciones atestiguadas por la existencia de ejemplares, la nómina alcanzaría el número de 88 , abarcando desde el supuesto incunable burgalés hasta las ediciones bilingües de Rouen con las que se trataban de burlar las enmiendas sufridas por la obra desde 1632 .

Es una certeza entre los críticos la pérdida de ediciones tanto de la Comedia como de la Tragicomedia, que permite sospechar que la difusión impresa de Celestina tuvo que ser muchísimo más rica, alcanzando, sin duda, el centenar de ediciones. Las referencias de bibliógrafos del pasado, los catálogos de bibliotecas desaparecidas o dispersas, las anotaciones en ejemplares, los índices inquisitoriales o las licencias concedidas a impresores, etc., son algunas de las muchas vías que nos proporcionan pistas sobre ediciones desconocidas, aunque también pueden inducir a error y conducirnos hacia otras imaginarias, los testimonios «fantasmas» tan temidos por todo bibliógrafo. En algunos casos, sin embargo, las evidencias llevan a pensar que pisamos terreno firme al presuponer su existencia $y$, en otros casos - los mejores- son los hallazgos inesperados los que ponen fin a la incertidumbre.

Hay coincidencia entre los bibliógrafos en aceptar la existencia de un impreso de 1500, al que aludiría Alonso de Proaza en su colofón rimado:

I El carro Phebeo defpues de auer dado I mill $\tau$ quinientas bueltas en rueda I ambos entonçes los hijos de Leda I a Phebo en fu cafa tenien polfentado: I quando efte muy dulce y breue tratado I defpues de reuifto $\tau$ bien

1.- Este trabajo se ha realizado en el marco del Proyecto de Investigación PID2019104989GB-I00, concedido por el Ministerio de Ciencia e Innovación. Se inscribe en el grupo investigador 'Clarisel', que cuenta con la participación económica tanto del Departamento de Ciencia, Tecnología y Universidad del Gobierno de Aragón como del Fondo Social Europeo. Para la información inicial retomamos algunos datos de $\mathrm{M}^{\text {a }}{ }^{J}$. Lacarra, "Testimonios recuperados de La Celestina (Sevilla, 1569 y Salamanca, 1573) y de una Glosa del Cartujano a las Coplas de Manrique (Medina del Campo, 1569)", en Homenaje a Giuseppe Mazzocchi. Cauterio suave. Collana di filologia ibérica fondata da Giuseppe Mazzocchi diretta da Paolo Pintacuda, en prensa. Agradecemos la inestimable ayuda de Dorothea Schoch, Patrizia Botta, Mercedes Fernández Valladares, Francisco J. Lobera, María Cristina Misiti e Inmaculada García-Cervigón del Rey.

2.- Para más detalles de estas ediciones, cfr. M. ${ }^{a} J$. Lacarra, «Fernando de Rojas, Celestina», en Comedic: Catálogo de obras medievales impresas en castellano hasta 1600, Zaragoza (España), ISSN 2530-1985 [en línea]. Publicación: 15-03-2019. Actualización: 31-12-2020. DOI: < https://doi.org/10.26754/uz_comedic/comedic_322> [Fecha de consulta: 20-10-2021]. 
corregido I con gran vigilancia puntado y leydo I fue en Salamanca impreflo acabado. II (70r) ${ }^{3}$.

De ahí la deducción de una posible edición salmantina perdida, en la que también habría colaborado Proaza y que, según Víctor Infantes, pudo haber salido entre mayo o junio para ajustarse a la metáfora cronológica ${ }^{4}$. Desconocemos también dónde y cuándo pudo imprimirse la princeps de la Tragicomedia, de la que derivaría el impreso zaragozano de 1507 así como la traducción italiana de Alfonso Ordóñez (Tragicomedia di Calisto e Melibea novamente traducta de spagnolo in italiano idioma, Roma: Eucharius Silber, 1506), puesto que todas las ediciones datadas en 1502 son posteriores; se han propuesto, entre otros, un impreso de Salamanca de 1502, o uno toledano de 1504 , en ambos casos sin ejemplares.

Solo en 2017 hubo dos importantes hallazgos de testimonios con el falso colofón sevillano de 1502. Ottavio Di Camillo localizó en Nápoles un ejemplar, identificado por Mercedes Fernández Valladares como salido del taller de Juan Varela de Salamanca, circa 1514-1517, y Charles Faulhaber encontró en Erfurt otro impreso celestinesco, que Julián Martín Abad atribuye a la oficina tipográfica de Jacobo Cromberger hacia $1516^{5}$.

3.- Valencia: Juan Joffre, 1514, 21 de febrero, Biblioteca Nacional (España), sig. R/4870. Disponible en: <http://www.cervantesvirtual.com/obra/tragicomedia-de-calisto-y-melibeanueuamete-reuista-y-emendada-co-addision-de-los-argumetos-de-cad-0/> [Fecha de consulta: 20-10-2021].

4.- Según Norton, Alonso de Proaza se limitaba en 1514 a repetir la fecha de una edición salmantina perdida de la Comedia fechada en 1500, tal vez la primera en la que él hubiese intervenido, lo que le llevaba a concluir: "Que hubiese una edición de Salamanca de un texto de La Celestina de 1500 es casi imposible ponerlo en duda»; cfr. F. J. Norton, "Appendix B. The early editions of the "Celestina"", en Printing in Spain, 1501-1520, Cambridge, Cambridge University Press, 1966, p. 147; citamos por la traducción española, «Apéndice B. Las primeras ediciones de la "Celestina"”, en La imprenta en España 1501-1520, ed. J. Martín Abad (con un nuevo «Índice de Libros Impresos en España, 1501-1520»), Madrid, Ollero y Ramos, 1997, p. 214. También vid. V. Infantes, «El laberinto cronológico y editorial de las primitivas impresiones de Celestina (1497-1514). Con una Marginalia bibliographica al cabo [y una nota final]», en La trama impresa de Celestina. Ediciones, libros y autógrafos de Fernando de Rojas, Madrid, Visor Libros, 2010, p. 16 (primera edición en Actas del Simposio Internacional «1502-2002: Five Hundred Years of Fernando de Rojas» "Tragicomedia de Calisto y Melibea» (18-19 de octubre de 2002), Bloomington, Indiana University - Departamento de Español y Portugués, 2007).

5.- En el primer caso se trata de un testimonio único, localizado por O. Di Camillo. Nápoles. BNN: Sala D. Quatrocent. XXIII-C-3(1), encuadernado junto a la Cárcel de amor (Sevilla: Jacobo Cromberger, 1520, 11 de enero) y que, según anotación manuscrita, habría pertenecido a la biblioteca del cardenal don Cristóbal Melgarejo. Los recientes estudios de M. Fernández Valladares han permitido atribuirlo al taller sevillano de Juan Varela de Salamanca, ca.15141517; cfr. M. Fernández Valladares, "Otra enigmática Tragicomedia de Calisto y Melibea con la data contrahecha de «1502»: análisis tipográfico y ensayo de ecdótica iconográfica (con una nueva edición de la Cárcel de amor (1520)», en Literatura medieval hispánica: "Libros, lecturas y reescrituras", coord. M. a J. Lacarra, eds. N. Aranda García, A. M. Jiménez Ruiz y A. Torralba Ruberte, San Millán de la Cogolla, Cilengua, 2019, pp. 463-501. El segundo corresponde también a un testimonio único, localizado por C. Faulhaber en la biblioteca de la Universidad de Erfurt (03 Lp. $8^{\circ}$ 00550). Cuenta también con éxplicit rimado en 1502 , pero ha sido datado por J. Martín 
En 2018 se incorporó a la serie una nueva Celestina desconocida, esta vez de Pedro Bernuz (1554), cuyo hallazgo ha pasado más inadvertido para los estudiosos celestinescos. El punto de partida de este impreso zaragozano es otro publicado diez años antes en la misma ciudad (1545), cuando el taller lo regían Pedro Bernuz y Bartolomé de Nájera, de gran interés desde el punto de vista gráfico, puesto que tiene todos los actos decorados con escenas y no con figuritas. Esta oficina tipográfica es resultado de las sucesivas ventas que hizo Jorge Coci a partir de 1536, cuando doce años antes de su muerte, viudo y sin hijos, empezó a desvincularse de su negocio. Esta circunstancia explica que ambos impresores conservaran su instrumental y quisieran seguir utilizando su nombre y su marca como garantía de calidad. La unión entre el librero Bartolomé de Nájera, uno de los hombres de confianza de Coci, y el notario Pedro Bernuz, cuya esposa, Isabel Rodríguez, era sobrina del alemán, se extendió entre 15401546; a partir de esas fechas se disolvió la sociedad y ambos emprendieron su actividad en solitario, distribuyéndose los enseres del taller ${ }^{6}$. Este testimonio, actualmente en una biblioteca particular, fue impreso por $\mathrm{Pe}$ dro Bernuz, con colofón del 22 de noviembre de 1554. La coincidencia de las estampas muestra que fue este impresor y notario de caja quien se hizo con los tacos ${ }^{7}$. Las 26 imágenes que ilustran el texto - deberían ser 27, pero el modelo está mútilo- proceden de las mismas entalladuras de la edición anterior y los únicos cambios se producen en la mención de la portada («en la officina de Pedro Bernuz. Año de.M.D.XLIIII»); en la marca, con un taco de nueva elaboración en la que figura su propio monograma; y en la incorporación del tipo de la coma en la fundición.

Por nuestra parte, a estas ediciones hemos sumado otras dos, que no dejan de ser un reflejo de la progresiva decadencia de la imprenta espa-

Abad en 1516, antes de abril. En línea: J. Martín Abad, "Una nueva edición "Sevilla, 1502"», PhiloBiblon, Abril 22, 2017, <https://update.lib.berkeley.edu/2017/04/22/la-tragicomedia-decalisto-y-melibea-de-sevilla-1502-una-nueva-edicion/> [Fecha de consulta: 20-10-2021].

6.- M. J. Pedraza Gracia, «La imprenta zaragozana del impresor Pedro Bernuz a través de los protocolos del notario Pedro Bernuz II», Revista Zurita, 72 (1997), pp. 29-52; M. J. Pedraza Gracia, "Los talleres de imprenta zaragozanos entre 1475 y 1577», Pliegos de Bibliofilia, 11 (2000), pp. 3-22; y M. J. Pedraza Gracia, "Por George Coci, alemán», en La literatura medieval hispánica en la imprenta (1475-1600)", eds. M. ${ }^{a}$ J. Lacarra y N. Aranda, Valencia, Prensas de la Università de València, 2016, pp. 201-214.

7.- F. de Rojas, La Celestina, ed. de M. R. Moralejo Álvarez, facsímil no venal, Sabadell, 2018; ejemplar del coleccionista Alfonso Fernández González. Para la descripción de esta edición, véase M. ${ }^{a}$ J. Lacarra, "La tradición iconográfica de la Tragicomedia de Calisto y Melibea (Zaragoza: Pedro Bernuz y Bartolomé de Nájera, 1545)», en Avatares y perspectivas del medievalismo ibérico, ed. I. Tomassetti, San Millán de la Cogolla, Cilengua, 2019, pp. 1684-1696. Para el modelo iconográfico de sus grabados, véase, A. Saguar García, «ìUn programa iconográfico original? Modelos alemanes para los tacos de la edición Zaragoza, en la oficina de Jorge Coci a costa de Pedro Bernuz y Bartolomé de Nájera, 17 de junio de 1545, de Celestina», en Videoactas del I Congreso del CELPYC (4-5 de junio de 2020), eds. E. Fernández y A. Saguar García, Nueva York, CELPYC, 2020, vídeo 11. <https://doi.org/10.47537/celpyc2020.11>. 
ñola en la segunda mitad del Quinientos. La primera es una sevillana, de la que se tenían noticias, pero hasta ahora carecíamos de ejemplar documentado. Se trata de un impreso sevillano de Alonso de la Barrera, datado en 1569. De esta edición, citada por bibliógrafos desde el siglo XIX, hemos podido localizar un ejemplar en la Biblioteca municipal de Nantes. A ella añadimos también una edición salmantina, hasta ahora no recogida en ningún catálogo según nuestros datos, de la que consta un ejemplar en la biblioteca estatal de Vorarlberg, ubicada en la ciudad de Bregenz (Austria).

A finales de febrero del año 2020, cuando el covid-19 impedía el acceso a las bibliotecas, el profesor Neil Harris, de Udine, llamó la atención sobre un ejemplar de Celestina conservado entre los fondos de la Biblioteca Comunale Valentiniana de la ciudad de Camerino, en la provincia de Macerata. A las circunstancias de la pandemia se suman las consecuencias del terremoto de 2016, sufrido especialmente en esta zona italiana, lo que hace imposible de momento el acceso a los fondos para poder verificar las características de esta edición. El ejemplar, incluido por Carlo Pasero en el catálogo de los fondos antiguos de esta biblioteca, es un volumen en $4 .^{\circ}$, encuadernado junto al Sumario dela capitulacion assentada et firmada entre la cesarea catholica y real magestad del emperador y rey nuestro senor y el Christianissimo rey de Francia, Romance del conde Claros de Montaluna y Romance del Conde Claros nuevamente trobado por otra manera. Su colofón ("Acabasse la Tragicomedia con el tratado de Centurión con diligencia corregido y emendado. Impresso por Jacobo Cromberger aleman y Juan Cromberger. Año del señor de M.d.xxv. en fin de Noviembre») coincide con el del testimonio conservado en la British Library (G.10223), pero se diferencia en algunos detalles de la portada y del fol. a2r —únicas hojas con reproducción hasta ahora- de este testimonio único. En la portada, al título y subtítulo conocidos ("Tragicomedia de Calisto y Melibea, en la cual se contienen de más de su agradable y dulce estilo muchas sentencias filosofales y avisos muy necessarios para mancebos mostrándoles los engaños que están encerrados en servientes y alcahuetas») les falta el anuncio: "e nuevamente añadido el tractado de Centurio", lo que comporta otros ajustes. En las octavas acrósticas se puede observar la tendencia al uso de formas completas y no abreviadas. Es posible que estemos ante la misma edición del ejemplar conservado en Londres, pero de una emisión diferente; una hipótesis que, de momento, solo puede aventurar$\mathrm{se}^{9}$. A las anteriormente mencionadas, podemos añadir ahora un curioso testimonio conservado en una biblioteca alemana.

8.- Para más datos, cfr. M. a J. Lacarra, "Testimonios recuperados de La Celestina...», art. cit.

9.- La ficha en el catálogo conjunto de las Bibliotecas de Ascoli Piceno, Fermo y Macerata es accesible en: https://bibliomarchesud.it/opac/resource/tragicomedia-de-calisto-y-melibea-/UMC0718703. Para la formación de la Biblioteca, véase D. Branciani y P. L. Falaschi, «La Biblioteca Comunale Valentiniana di Camerino", Lettere dalla Facoltà, 7.4 (2004), pp. 24- 29. 


\section{El fondo Schad en la biblioteca estatal de Ulm}

La biblioteca del estado de Baden-Wurtemberg cuenta con un interesante fondo antiguo, legado de los descendientes de Erhard Schad (16041681). Este jurista alemán, miembro de una de las más antiguas familias patricias de la ciudad, se formó en Estrasburgo, Tubinga, Altdorf y Padua. En 1628 se estableció en Milán, donde se centró en el estudio de la lengua y la literatura italianas, y pudo adquirir gran parte de sus libros ${ }^{10}$. Posteriormente regresó a Alemania con una amplia biblioteca, y falleció en 1681. En la iglesia del pueblo de Geislingen, de donde fue alguacil desde 1651 hasta su muerte, está su tumba con un epitafio que dice: «Erhard Schad era un amante de los libros y las antigüedades que viajaba mucho y tenía una gran formación científica; su biblioteca contenía 13.900 libros».

Según dispuso en su testamento datado en 1678, sus fondos pasarían a ser propiedad de la ciudad de Ulm si la familia no tenía heredero varón. Pese a que en 1826 esta condición no se cumplía, el 13 de enero sus descendientes decidieron aplicar esta disposición testamentaria y donaron la biblioteca a la ciudad. El catálogo más antiguo de los bienes de Schad fue preparado por su propietario, aunque hay 32 entradas que corresponden a fondos de su padre, Conrad. Los cerca de 14000 títulos muestran su afición por los libros hermosos, con unos 45 incunables, algunos únicos, como la obra de Lorenzo Spirito, Libro della ventura, ovvero Libro delle sorti, de 1482. Unos 5880 volúmenes corresponden al siglo xvi, muchos de ellos ilustrados, y reflejan su conocimiento de las lenguas extranjeras con obras en alemán, latín, griego, italiano, francés y español, principalmente.

Entre sus fondos españoles predominan los clásicos publicados fuera de España, como el Quijote, el Lazarillo o el Guzmán de Alfarache, en ediciones milanesas; tanto en su lengua original como traducidos al alemán o al italiano, como es el caso del Amadís de Gaula o la Diana de Montemayor; y un gran número de ediciones de los Países Bajos, como los escritos de Teresa de Jesús o de Francisco Castaña, Huarte de San Juan, Antonio de Guevara, etc. Entre los impresos del XVI sobresalen algunos ejemplares

La única referencia hasta ahora se encontraba en C. Pasero, Incunaboli ed edizioni cinquecentesche nella Biblioteca Valentiniana e comunale di Camerino, Camerino, Stab. tip. Successori SaviniMercuri, 1933, n. CCXXXIV. Para su hallazgo, véase el Blog de A. Saguar García, Por treze, tres (https://portrezetres.hypotheses.org/page/2) y la interesante actualización de datos de C. Faulhaber, "Una nueva emisión de la edición de Sevilla: Cromberger, 1525, de Celestina», 7 de marzo de 2020, blog de Philobiblon <https://update.lib.berkeley.edu/2020/03/07/una-nuevaemison-de-celestina-sevilla-cromberger-1525/> [Fecha de consulta: 20-10-2021].

10.- Agradecemos los datos a Dorothea Schoch, quien nos ha facilitado el acceso al catálogo elaborado por el propio Schad, precedido de una breve introducción: B. Appenzeller, D. Schoch und A. Rosenstock, Catalogus Schad. Die Bibliothek des Erhard Schad (1604-1681), Ulm, Stadtbibliothek Ulm, 2013; B. Breitenbruch, «Die Bibliothek des Ulmer Patriziers Erhard Schad», Ulmer Forum, 59 (1981), pp. 11-13. Disponible en: <https://stadtbibliothek.ulm.de/ online/die-stadtbibliothek-veroeffentlicht-online> [Fecha de consulta: 20-12-2021]. 
únicos o poco conocidos, no incorporados a veces a los catálogos tradicionales. De acuerdo con la descripción de su poseedor destacan:

San Pedro, Diego Fernández de: Question de amor y carcel de amor. - Enueres: Nutius, 1546. [480] S. - Vorlageform des Erscheinungsvermerks: Fue impreso en Enueres eel vnicornio doro par Martin Nucio. M.D.XLVI. Außerdem enthalten: Carcel de amor del complimiento de Nicolas Nunez. Schad 6905.

Sepúlveda, Lorenzo de: Cancionero de romances nuevamente sacados de historias antiguas de la cronica de Espana ... Medina del Campo: Boyer, 1576. 272, [4] Bl. Schad 6906.

Timoneda, Juan de: Rosa de amores: primera parte de romances. - Lerida: Villanueva \& Robles, 1574 [ersch.] 1575. 59, [2] Bl. -Vorlageform des Erscheinungsvermerks: Impressos, ano de 1574. Kolophon: Fue Impressa esta primera parte de Romances de amores en la Ciudad de Lerida enla Emprenta de Iuan de Villanueua y Pedro de Robles. Ano 1575 Schad $6907^{11}$.

\section{1. Celestina en la Biblioteca estatal de Ulm}

A estos testimonios se suman dos ediciones de Celestina del siglo XVI cuyas entradas son:

Nuevamente revista y emendada con addicion delos argumentos de cada un auto en principio co[n] addicion delos argume[n]tos de cada un auto en principio, la qual co[n]tiene de mas de su agradable y dulce estilo muchas sente[n]cias filosofales y avisos muy necessarios pa ma[n] cebos mostra[n]do les los engan[n]os q. estan encerrados en sirvie[n]tes y alcahuetas [Sevilla], $\neg[\mathrm{ca} . \neg 1515 \neg] \neg[82]$ B1.: Ill Schad 4434

Tragicomedia de Calisto y Melibea, en la qual se contienen de mas de su agradable y dulce estilo, muchas sen-

11.- La edición conjunta de la Cárcel de amor y la Questión de amor fue considerada testimonio único por J. F. Peeters Fontainas, L'officine espagnole de Martin Nutius à Anvers, Anvers, Societé des Bibliophiles Anversois, 1956, n. 9, aunque existen otros ejemplares en Madrid, Biblioteca Nacional, Nueva York, Hispanic Society y en la Biblioteca Nacional de Viena. El volumen de Sepúlveda fue incorporado por P. M. Cátedra en su Estudio preliminar a la reedición facsímil de la obra de Cristóbal Pérez Pastor, La imprenta en Medina del Campo, Valladolid, Junta de Castilla y León, 1992, n. ${ }^{\circ}$ 188. V. Beltran, en su edición de Joan Timoneda, Rosas de Romances, México D. F., Frente de Afirmación Hispanista, 2018, considera que esta edición leridana es un testimonio único. 
tencias filosofales y auisos muy necessarios para mançebos, mostrandoles los engaños que estan encerrados en siruientes y alcahuetas [Antwerpen]: Plantin, 1595352 S. Schad 5887

La edición plantiniana es una de las más difundidas por toda Europa con más de treinta ejemplares conservados, pero la primera es un testimonio especialmente interesante cuyas particularidades pretendemos detallar en esta publicación. Como todos los volúmenes, está marcado en el vuelto de la cubierta con el exlibris de su propietario, consistente en una cartela ricamente adornada con volutas, vegetales y guirnaldas y en un óvalo central, blasón de la familia Schaden con el escudo (en campo de oro) con un águila explayada en sable, y sobre el casco, adornado con lambrequines, la misma águila a modo de cimera. El coleccionista añadía al exlibris una divisa manuscrita en distintas lenguas, muchas veces sacada del fondo proverbial ${ }^{12}$; en este caso se trata de la cita cervantina «Buen coraçon quebranta mala ventura", recogida por Correas $^{13}$ :

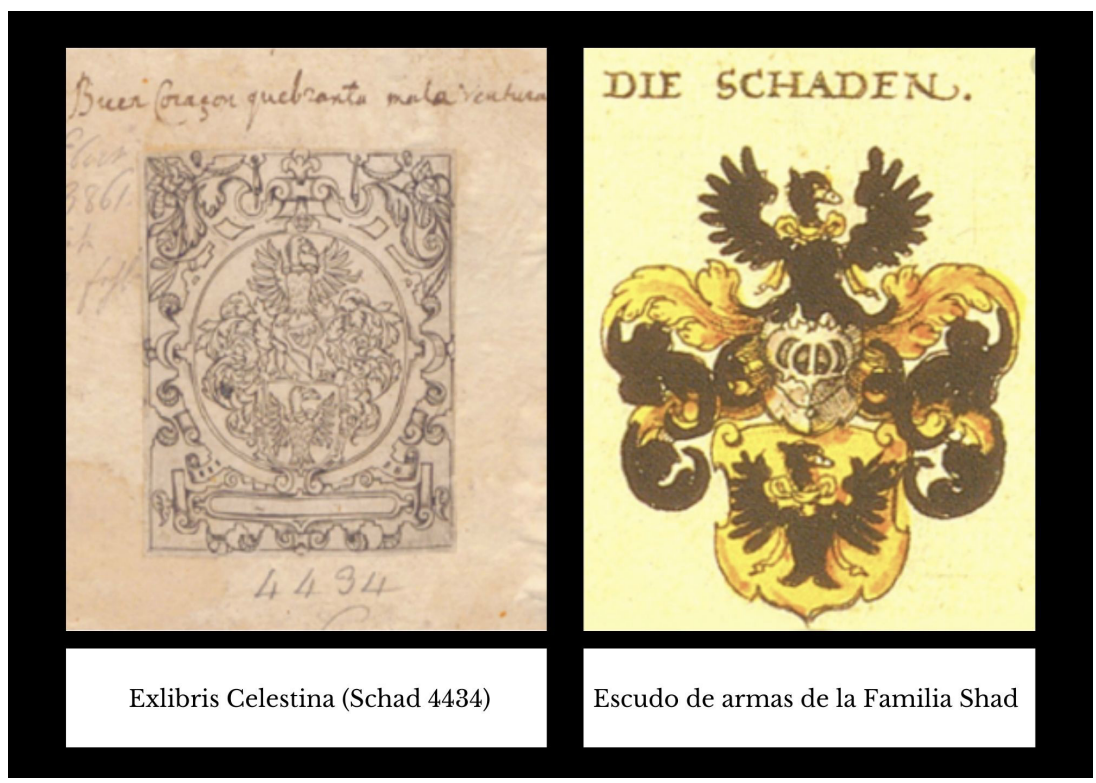

Lámina 1

La excepcionalidad del primer ejemplar celestinesco conservado por Schad reside en ser un testimonio manipulado a partir de la fusión de dos

12.- «Wappen Ulmer Patrizierfamilie Schad», en H. Appuhn (ed.), Johann Siebmachers Wappenbuch. Die bibliophilen Taschenbücher, Harenberg, Aufl, Dortmund, 1989, 2. verb, n. 538.

13.- G. Correas, Vocabulario de refranes y frases proverbiales (1627), ed. L. Combet, revisada por R. James y M. Mir-Andreu, Madrid, Castalia, 2000, B334; Quijote, II, 10 y II, 35. 
ediciones en cuarto: por una parte, la edición impresa por Juan Jofré en Valencia, el 21 de febrero de $1514\left(\mathrm{~A}^{2}-2 \mathrm{~h}\right.$.) y, por otra, una nueva edición que atribuimos a Marcelo Silber y que fue impresa en Roma con anterioridad a $1515\left(\mathrm{~B}-\mathrm{T}^{4}, \mathrm{U}^{6}-78 \mathrm{~h}\right.$.). En la misma línea de los descubrimientos de 2017, esta última se incardina en las ediciones que incluyen el famoso éxplicit rimado con la contrahechura de "Sevilla 1502".

A partir de los principios tipobibliográficos ${ }^{14}$ y biblioiconográficos ${ }^{15}$, posteriormente respaldados por los de la ecdótica y la crítica textual, ofrecemos un análisis material detallado de este curioso ejemplar facticio.

\section{2. 1. Cuaderno $\left(A^{2}\right)$ del Ejemplar de Ulm (Schad 4434)}

Las dos primeras hojas que constituyen este ejemplar incluyen la portada (con grabado, título - «Tragicomedia de Calisto y Melibea»- con el anuncio de «nuevamente revista y enmendada... ${ }^{16}$ ) y parte de los característicos preliminares de la tradición editorial celestinesca. A la carta de «El autor a un su amigo» le siguen las octavas que incorporan el famoso acróstico «El bachiller Fernando de Rojas acabó la Comedia de Calisto y Melibea e fue nascido en la Puebla de Montalbán». Si bien, del total de once octavas, este ejemplar solamente contiene nueve, ya que al pasar del fol. $2 \mathrm{v}$ al fol. $3 \mathrm{r}$, la décima octava ("Amonesta a los que aman que sirvan a Dios y de / jen las vanas cogitaciones y vicios de amor») se ve interrumpida para dar lugar a la parte final del prólogo («turas: poniendo rúbricas: o sumario al principio de cada acto [...] puesto que no han de faltar nuevos detractores a la nueva adición») que precede al íncipit «Síguese la Comedia o Tragicomedia...».

Podríamos considerar que la ausencia de las dos últimas hojas del cuaderno A estaría justificada por un inevitable deterioro del testimonio, ocasionado por el transcurso del tiempo o por la manipulación humana, lo cual habría dado paso directo al cuaderno B. Sin embargo, un cotejo

14.- Para la etapa post-incunable, cfr. H. D. L. Vervliet, Sixteenth-century printing types of the Low Countries, Leiden, Brill, 1968; F. J. Norton, A descriptive catalogue of printing in Spain and Portugal 1501-1520, Cambridge, Cambridge University, 1978.

15.- M. Fernández Valladares, «Biblioiconografía y literatura popular impresa: la ilustración de los pliegos sueltos burgaleses (o de babuines y estampas celestinescas)", eHumanista. Journal of Iberian Studies, 21 (2012), pp. 87-131; M. Fernández Valladares, «De la tipobibliografía a la biblioiconografía: consideraciones metodológicas para un Repertorio digital de materiales iconográficos de los impresos españoles del siglo XVI», en Actas del Simposio sobre El libro en el mundo hispánico: nuevas tendencias y direcciones (Magdalen College, Oxford, 20-21 de septiembre de 2010), eds. J. C. Conde y C. Griffin, New York, Hispanic Seminary of Medieval Studies, 2020, pp. 57-98.

16.- «nueuamēnte reui | Ita y emendada cō addicion delos argu I mētos de cada vn auto en paincipio. la | qual cōtiene de mas de fu agradable $\tau \mid$ dulce eftilo muchas fentēcias filofofa $\approx \mid$ les: $\tau$ auifos muy neceffarios pa māce | bos: moltrādo les los engaños $\tilde{q}$ eftan I encerrados en firuiētes $\tau$ alcahuetas». Precisamente este paratexto es el que encabeza la entrada del ejemplar de la Biblioteca Estatal de Ulm (Schad 4434). 
entre la caja de escritura y la letrería de los fols. 2v-3r (ca. 82G y 41 líneas frente a una gótica $85 \mathrm{G}$ y 37 líneas, respectivamente), así como la costura interna y los dos tipos de marginalia - con diferente tinta e idioma, italiano en el primer caso y español en el segundo- permiten confirmar la falsificación de este ejemplar ${ }^{17} \mathrm{y}$, por tanto, la presencia de, al menos, dos ediciones distintas en el mismo (Lámina 2).

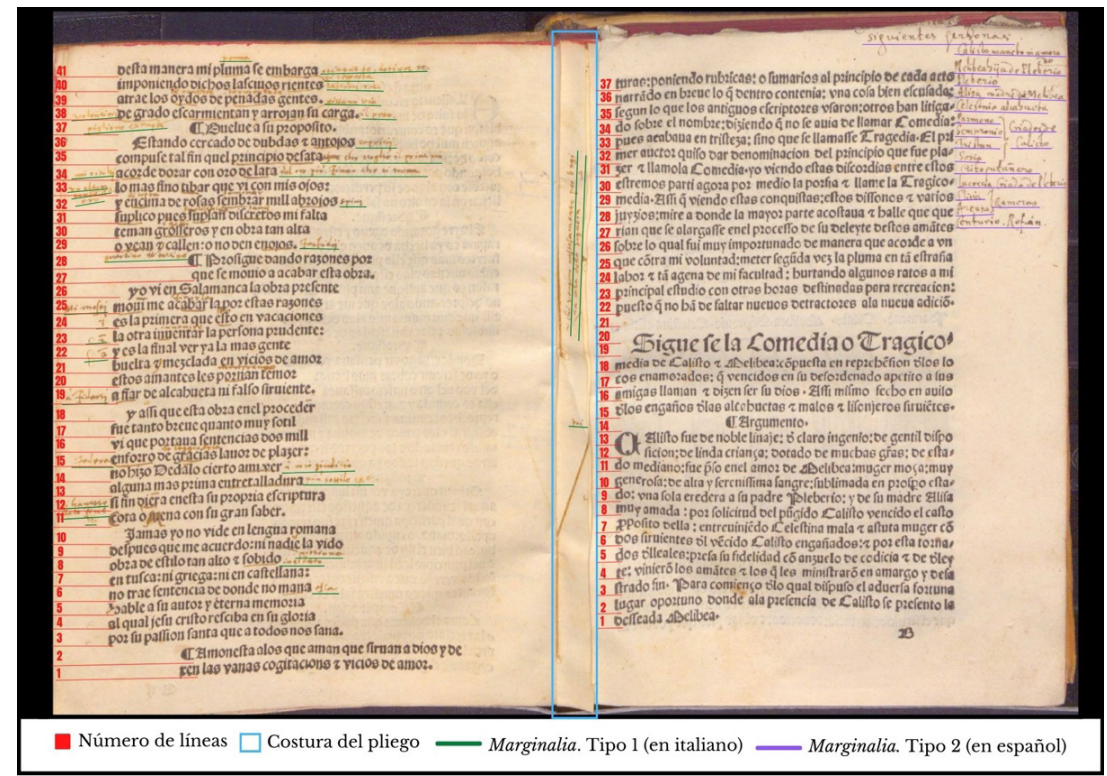

\section{Lámina 2}

Gracias al grabado xilográfico que encabeza el primer cuaderno, la identificación de esta primera parte apenas deja resquicio al misterio, ya que es la misma ilustración empleada en las portadas de las ediciones valencianas publicadas por Juan Jofré. El análisis sinóptico entre Ulm y las ediciones de Jofré revela que las dos hojas del cuaderno A pertenecen a la edición de 1514, y no a la edición de 1518 ni a una edición desconocida.

\section{2. 2. Cuadernos $\left(B-T^{4}, U^{6}\right)$ del Ejemplar de Ulm (Schad 4434)}

Por lo que respecta al resto de cuadernos que constituyen este ejemplar, nos encontramos ante una edición sine notis desconocida hasta la fecha que hemos denominado CUlm.

17.- Desde la Stadtbibliothek Ulm nos confirman que se han añadido los fol. A1 y fol. A2 a la encuadernación y que su papel difiere del resto de hojas del ejemplar. Creemos que fue adquirido en Italia por Schad en estas condiciones y que no fue manipulado con posterioridad. Sin embargo, esta premisa debe ser confirmada tras una inspección directa del ejemplar (una operación que no ha podido llevarse a cabo debido a las restricciones producidas por la pandemia). 
Al faltar el primer cuaderno - en cuya portada en ocasiones aparecía el nombre del impresor - la única información paratextual que permitiría localizar y datar esta ignota edición es el cronotopo "Sevilla 1502» que se incluye dentro del éxplicit rimado de los paratextos finales ${ }^{18}$. Por ello, conviene aproximarse a las primeras ediciones de la Tragicomedia nacidas en Castilla que incluyen esta contrahechura destinada en origen a eludir la censura ${ }^{19}$.

El texto principal de esta Tragicomedia está compuesto en una tipografía que da lugar a una caja de escritura de hasta 38 líneas. Si nos atenemos a la tendencia editorial de las Celestinas de las primeras décadas del siglo XVI, que progresivamente incluían tipos menores para conseguir un ahorro en pape ${ }^{20}$ - la principal fuente de gastos de la industria editorial antigua ${ }^{21}$ - la configuración de esta segunda parte de nuestro ejemplar la acerca a las primeras Tragicomedias conservadas: la edición zaragozana de 1507 presenta 38 líneas y el número aumenta con las 41 líneas de las ediciones cromberguerianas (ca. 1511, ca. 1513-1515, ca. 1516, ca. 1518-

18.- Se trata de la última copla de Proaza que desde la Comedia, como bien ha señalado la crítica, actúa como colofón de la obra: «El carro de Febo después de haber dado / mil y quinientas dos vueltas en rueda / ambos entonces los hijos de Leda / a Phebo en su casa tienen posentado / cuando este muy dulce y breve tratado / después de revisto y bien corregido / con gran vigilancia puntado y leído / fue en Sevilla impreso acabado» cfr. G. Serés, «Prólogo», en F. de Rojas (y "Antiguo Auctor»), La Celestina. Tragicomedia de Calisto y Melibea, eds. F. J. Lobera, F. Rico, G. Serés et al., Barcelona, Crítica, 2000, p. LVI (Subapartado: De la "Comedia" a la "Tragicomedia"). Para los paratextos de la Celestina véase, entre otros, M. Blanco, "Las piezas liminares de la Celestina: un vestíbulo enigmático", en La Célestine. Comedia o Tragicomedia de Calisto y Melibea. Actes du Colloque International, ed. F. Maurizi, Caen, Université de Caen, [1995], pp. 119-143; P. Botta, Edizione critica de La Celestina di Fernando de Rojas (atti VIII -XXI ${ }^{\circ}$, Roma, La Sapienza - Università di Roma- Fac. Lettere, 2001, [archivo Finales, Nota 1 y Nota 29, y archivo m-Finales, Nota 1 y Nota 25]. Consulta en línea: <http://rmcisadu.let.uniroma1.it/celestina/celest.htm>; F. Cantalapiedra Erostarbe, «Fue tanto breve quanto muy sutil. Los paratextos de La Celestina», eHumanista, 19 (2011), pp. 20-78.

19.- Actualmente son ocho las Tragicomedias que incluyen el falso colofón: Toledo: [Sucesor de Pedro Hagenbach], [1510-1514] (H); Sevilla: [Jacobo Cromberger], [1511] (I); Sevilla: [Jacobo Cromberger], [1513-1515] (K); Sevilla: [Juan Varela de Salamanca], [1514-1517] (CNa); [Roma: Marcelo Silber, 1515-1516] (J); Sevilla: Jacobo Cromberger, [1516] (Erfurt); [Sevilla: Jacobo Cromberger, 1518-1520] (L); [Roma: Antonio Blado, 1520] (M) [Seguimos los criterios de atribución de ciudad, impresor y fecha de Comedic, cfr. nota 1 y respecto a la crítica textual, la clasificación de las ediciones de J. H. Herriott, Towards a critical edition of the Celestina: a filiation of early editions, Madison [Wis.], University of Wisconsin Press, 1964]. Frente a los postulados de Norton e Infantes, Fernández Valladares —en consonancia con FoulchéDelbosc, Lobera-Rico-Serés y García Valdecasas- sostiene que los últimos descubrimientos (CNa y Erfurt) demuestran que la reiteración de la fecha 1502 en el éxplicit rimado se debió a la búsqueda de una elusión de la censura más que a una emulación de patrones editoriales cfr. M. Fernández Valladares, "Más evidencias bibliográficas para una controversia: el "colofón métrico" de la Celestina a la luz de las dos nuevas ediciones tempranas de la Tragicomedia ("Sevilla 1502")", en Controversia y producción escrita en la España Moderna, eds. M. Albisson y L. Sanz Gómez, Toulouse, Presses universitaires du Midi, 2019, pp. 215-228.

20.- M. Fernández Valladares, "Otra enigmática Tragicomedia...», art. cit., p, 469.

21.- P. Berger, Libro y lectura en la Valencia del Renacimiento, trad. Amparo Balanzá Pérez, València, Alfons el Magnànim, 1987, vol. I, pp. 146-147. 
1520), las 42 de Toledo (ca. 1510?) y de Valencia (1514 y 1518), y las 47 de la edición sevillana de Juan Varela (ca. 1514-1517).

La disposición de la caja de escritura y el programa iconográfico de los cuadernos - las ilustraciones siguen el modelo sevillano con grabados de ancho de página en los cinco principales actos y figuritas factótum en el resto ${ }^{22}$ - podrían ser indicio de que esta edición hubiera sido impresa en Sevilla en 1502 o, al menos, en torno a la fecha de la prínceps de la Tragicomedia. Si bien, un cotejo entre el tipo 85G empleado por Jacobo Cromberger - así como el de los toledanos de Hagembach (y Sucesor) y Varela, los salmantinos de Gysser y Porras, y los zaragozanos de Coci ${ }^{23}-$ y el tipo de CUlm revela una fuerte similitud en sus entalladuras. Sin embargo, la mayor inclinación de la doble cuerda del tipo crombergueriano demuestra que no nos encontramos ante el mismo juego tipográfico y, por tanto, CUlm no pudo haber salido de las prensas sevillanas de Cromberger (Lámina 3; figura a). Asimismo, el análisis sinóptico de los grabados de ancho de página evidencia que no estaríamos ante los mismos tacos empleados en las prensas cromberguerianas, sino ante una copia a espejo de ese modelo.

Por ello, es preciso ampliar el espectro de estudio y aproximarnos a las ediciones que emularon el patrón iconográfico sevillano. Es así cómo la disposición material de CUlm la relaciona directamente con la primera edición — conocida hasta la fecha - impresa en castellano en Roma: la edición de Marcelo Silber, circa 1515-1516 (J) $)^{24}$.

\section{2.- C. Griffin, «Celestina's Illustrations», Bulletin of Hispanic Studies, 78.1 (2001), pp. 59-79.}

23.- Aunque los tacos xilográficos apuntaban a Sevilla, también realizamos un cotejo tipobibliográfico siguiendo las premisas del trabajo de Infantes donde señala Toledo, Salamanca y Sevilla como posibles cunas de la prínceps de la Tragicomedia ("El laberinto cronológico...», cap. cit., pp. 58-90; esp. pp. 60-66) y también incluimos las prensas de Jorge Coci en Zaragoza ya que el testimonio más temprano conservado de la Tragicomedia procede de allí. De este modo, ni Hagembach (Norton, A descriptive catalogue..., op. cit., p. 366 ) ni su Sucesor (op. cit., pp. 370-371) contaron con un tipo gótico de este tamaño. Por su parte, Juan Varela de Salamanca utilizó un tipo 82G (tipo 10) en Toledo, en torno a 1512, que había obtenido del taller de Cromberger en ca. 1511, pero su entalladura dista morfológicamente de CUIm (op. cit., pp. 347-348). Asimismo, queda descartada toda aproximación a los talleres salmantinos Juan de Porras y Hans Gysser al no incluir el primer impresor tipos góticos de este tamaño y, en el caso de Gysser, presentar una entalladura muy distinta en el tipo 5 (82G) (op. cit., p. 165; p. 194). Respecto a las prensas zaragozanas de Coci, aunque el tipo 83-84G está presente desde 1497 y es el empleado para el cuerpo del texto de la Tragicomedia de 1507 (Z), la diferencia entre sus mayúsculas «M» revela que no pudo haber salido de este taller (op. cit., p. 220). El único tipo sevillano de Jacobo Cromberger con una medida y una entalladura similares al tipo 85G de CUlm había sido acuñado en torno a 1511 (op. cit., p. 284-285; C. Griffin, Los Cromberger. La historia de una imprenta del siglo XVI en Sevilla y Méjico, Madrid, Ediciones de Cultura Hispánica, 1991, p. 285). Si bien, un análisis minucioso demuestra que se trata de tipos diferentes. Véase la Lámina 3, figura a.

24.- Sobre esta edición cfr. C. Faulhaber, "The Heredia-Zabalburu Copy of the Tragicomedia de Calisto y Melibea, Sevilla, 1502 (i.e., Rome: Marcellus Silber, CA. 1516)", Celestinesca, 16.1 (1992), pp. 25-34; M. C. Misiti, «Alcune rare edizioni spagnole pubblicate a Roma da Antonio de Salamanca», en Libro antiguo español: actas del segundo Coloquio Internacional (Madrid), eds. M. L. López-Vidriero y P. M. Cátedra, Salamanca-Madrid, Universidad de Salamanca-Biblioteca Nacional de España: Sociedad Española de Historia del Libro, 1992, pp. 307-327; G. Olivetto, 
Desde un punto de vista tipobibliográfico, un cotejo de la «M» y de otras iniciales de CUlm y Roma [1515-1516] (Lámina 3; figura b) permite comprobar que la letrería empleada en CUlm fue la misma que Silber empleó en sus prensas. Se trata del juego de gótica (83-85G) ${ }^{25}$ que Marcelo Silber heredó de su padre Eucario, quien a su vez fue el impresor de la primera traducción italiana de Celestina ${ }^{26}$.

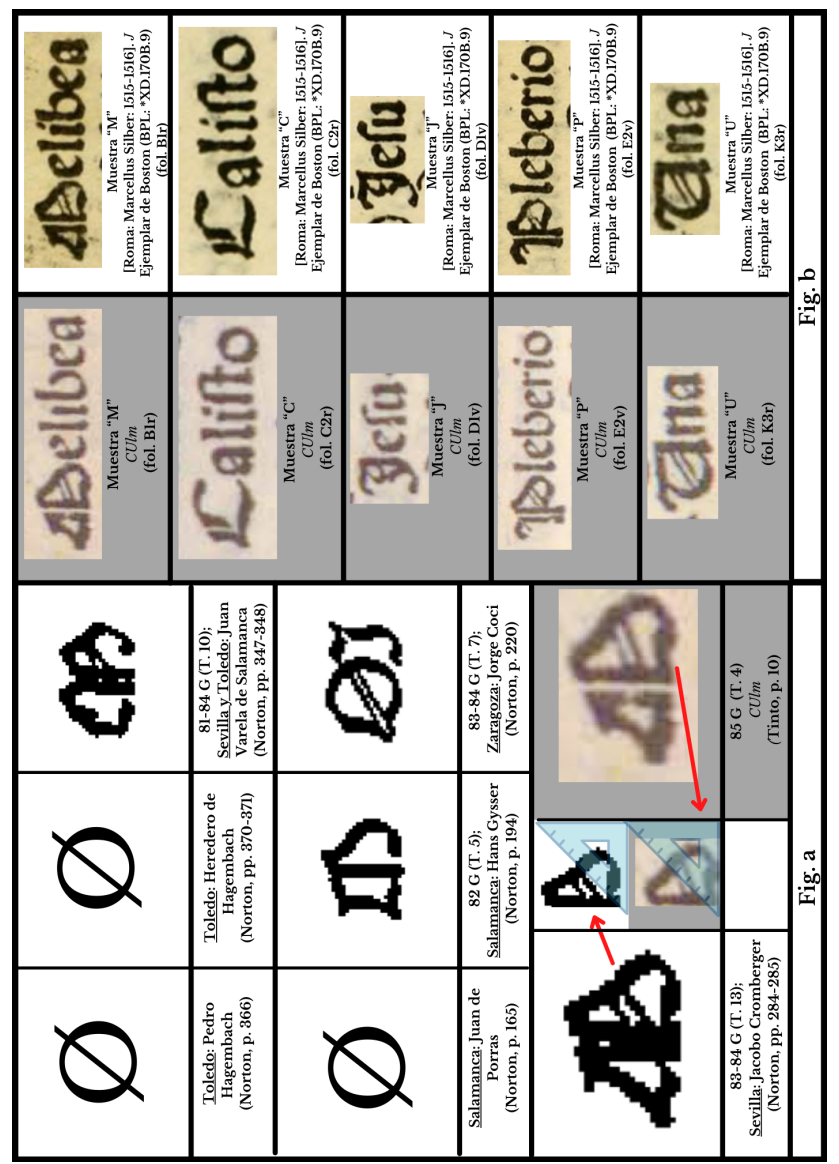

Lámina 3

«Ejemplares de Celestina de la Colección Foulché-Delbosc en la Biblioteca Nacional de la República Argentina», Celestinesca, 22.1 (1998), pp. 67-74.

25.- G.4 según la clasificación de A. Tinto, Gli Annali Tipografici di Eucario e Marcello Silber (1501-1527), Firenze, Olschki, 1968, p. 10.

26.- P. Botta, «La contaminación en N, la traducción italiana de La Celestina», Creneida, 4 (2016), pp. 107-121; O. di Camillo, "Algunas consideraciones sobre La Celestina italiana», en Rumbos del hispanismo en el umbral del Cincuentenario de la AIH, coord. P. Botta, Roma, Bagatto Libri, 2012, pp. 216-226. 
De igual modo, la estrecha relación entre CUlm y Roma [1515-1516] se hace palpable en el cotejo (Lámina 4) de los grabados de ancho de página de ambas ediciones y de las figuritas factótum - aunque la correlación entre estas no es la misma en todos los actos-, demostrando que los tacos usados en la edición de CUlm fueron los mismos que se emplearon en las prensas de Silber ${ }^{27}$. Al imitar fielmente los grabados xilográficos presentes en las ediciones de Cromberger, Norton calificaba la edición romana de ca. 1515-1516 de "edición pirata» de las sevillanas ${ }^{28}$. Del mismo modo, CUlm se inserta en esta misma tradición italiana que, precisamente, rompe la tendencia ahorradora de las Celestinas de la segunda década del Quinientos al emplear 82 hojas, probablemente debido al mayor número de reservas de papel en la península itálica.

27.- En julio de 2021 se realizó un estudio exhaustivo en las principales bibliotecas y fondos de Roma de las publicaciones realizadas por Silber en el periodo 1510-1525 y no se encontraron ediciones que reprodujeran en sus hojas las ilustraciones de los tacos xilográficos de ancho de página; un hecho que corrobora los postulados de M. C. Misiti ("Alcune rare edizioni...», art. cit.) al señalar a Antonio de Salamanca como el usuario y proveedor de los tacos de madera y como especial interesado en la producción de esta obra, del mismo modo que lo fue con los libros de caballerías y otros géneros editoriales exitosos de principios del Quinientos. Respecto al uso de figuritas factótum en las obras impresas por Marcelo Silber, además del conocido Concilio de los Galanes y Cortesanas de Roma invocado por Cupido de Bartolomé Torres Naharro (cfr. A. Rodrigo Moñino, Diccionario bibliográfico de pliegos sueltos poéticos (siglo XVI), edición corregida y actualizada por A. L.-F. Askins \& V. Infantes, Madrid-Mérida, Editorial Castalia - Editora Regional de Extremadura, 1997, n. 592); durante la consulta de ediciones en la Biblioteca A. Vaticana pudimos acceder al ejemplar del Introito et porta de quelli che voleno imparare et comprendere todescho, impreso en 1514, el 9 de febrero (cfr., A. Tinto, op. cit., pp. 99-100, n. 170) que incluye dos figuritas factótum en la portada (f. 1r) y otras dos en el vuelto (f. 1v). Aunque la referencia de Tinto es correcta (Stampe Ross. 4282), el título con el que está registrado puede dar lugar a equívoco: "Questo sie uno libro utilissimo a chi se dilecta di intendere Todescho dechiando in lingua Taliana». Aunque realizar una sistematización editorial de las prensas de Marcelo Silber excede los propósitos del presente trabajo, resulta muy interesante observar cómo los tipos en gótica y las figuritas factótum que salen de estas prensas se incluyen en obras que estaban destinadas a un público lector extranjero - Mirabilia Rome vrbis/Indulgentie ecclesiarum vrbis Rome - o interesado en el aprendizaje de otros idiomas, como es el caso de esta edición; unos datos que amplían las premisas de A. Bognolo, «El libro español en Venecia en el siglo XVI», en Rumbos del Hispanismo en el umbral de Cincuentenario de la AIH, coord. P. Botta, Roma, Bagatto Libri, 2012, pp. 243-258.

28.- J. Martín Abad, Post-incunables ibéricos, Madrid, Ollero \& Ramos, 2011, p. 458; F. J. Norton, «Las primeras ediciones...», cap. cit., pp. 219-220. 


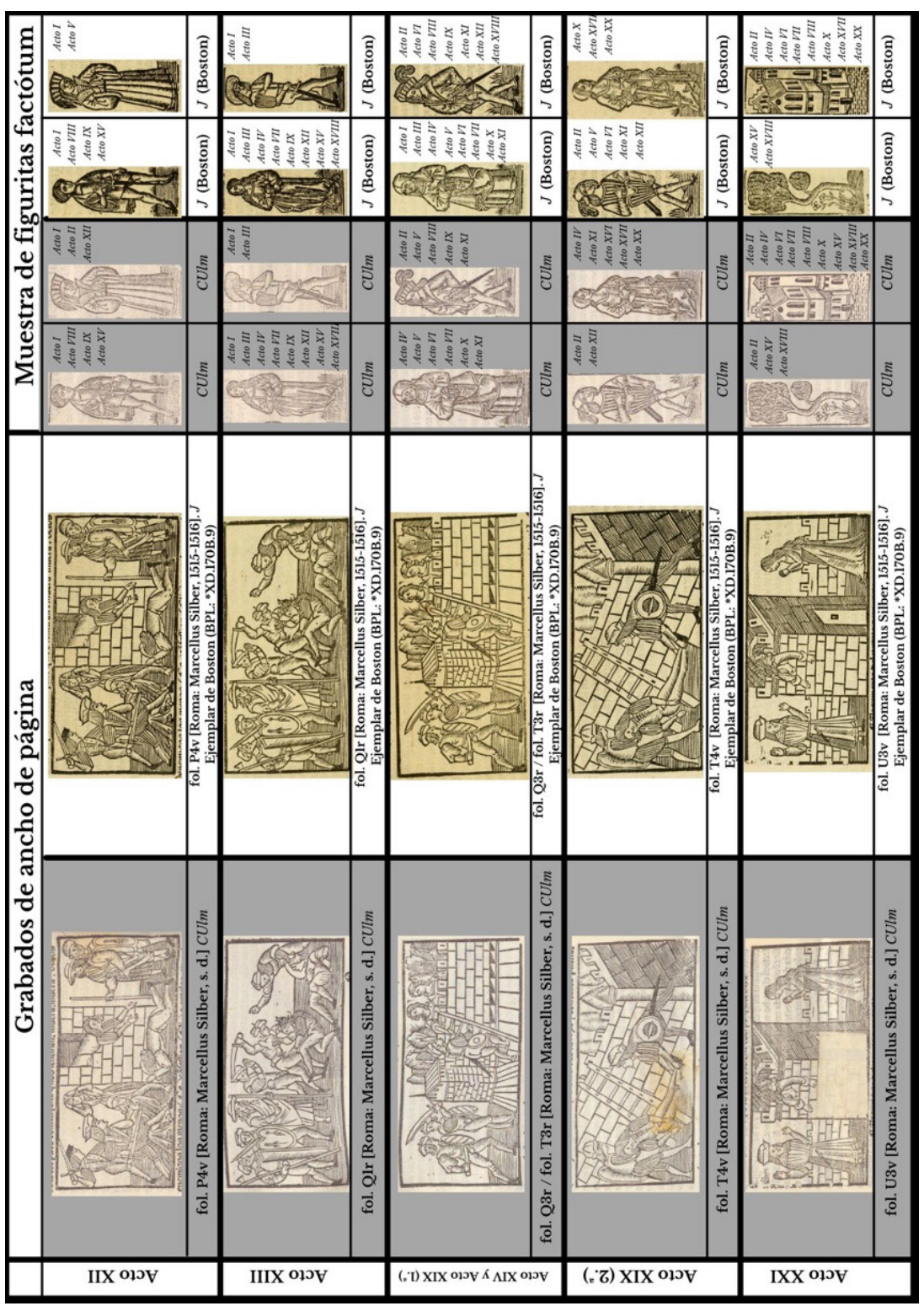

Lámina 4

Una vez localizada la imprenta en la que fue publicada, convenía preguntarse si esta segunda parte del ejemplar ulmiense podía ser una emisión de la ya conocida Roma [1515-1516] o podía ser una nueva edición totalmente desconocida, pues, de tratarse del segundo supuesto, la relación entre ambas había de ser muy próxima. 
Además de comprobaciones materiales como la prueba de la diagonal o la diferente disposición de las iniciales lombardas y de algunas figuritas factótum, la demostración fidedigna que revela que nos encontramos ante una nueva edición parte de un indicio tipológico y textual presente en el fol. U6r ${ }^{29}$ de CUlm.

En un primer y somero acercamiento, sorprende que el tipo de letrería empleado para la última hoja del cuaderno U - destinado a los paratextos finales- es distinto al utilizado en el resto de cuadernos, como lo demuestra la ausencia de doble cuerda o su menor tamaño (Lámina 5). Una vez descartada la posibilidad de que pudiera tratarse de una hoja añadida para confeccionar un ejemplar aparentemente completo $^{30}$, los tipos del fol. U6r coinciden con el juego G.3 (72G) de Marcelo Silber ${ }^{31}$. Estos se habían empleado para introducir en una misma plana las tres coplas de Rojas y las seis de Proaza, ya que el tipo 85G habría obligado a estampar el éxplicit rimado en el vuelto de la hoja. Aunque no habría implicado un mayor coste en papel, esta solución habría diluido la unidad visual - presente en las ediciones sevillanas a las que el ejemplar emula - de la parte final de la obra ${ }^{32}$. De hecho, es bastante probable que este fuera el problema con el que se encontraron los componedores de la edición de Roma [1515-1516], puesto que los tres ejemplares que conservan la última hoja (Boston, Buenos Aires y Trier) eliminan la quinta estrofa de Proaza manteniendo así todos los elementos paratextuales en la misma plana ${ }^{33}$ (Lámina 6).

29.- Patrizia Botta ya advertía de las variantes que se pueden producir entre diferentes ejemplares de una misma edición al ser el resultado de emisiones distintas, cfr. P. Botta, «Problemas filológicos de un texto impreso", Edad de Oro, XXVIII (2009), pp. 29-40.

30.- Lo confirma la inspección realizada por Dorothea Schoch de la Stadtbibliothek Ulm.

31.- Se trata de un juego que también heredó de su padre y que fue empleado para obras impresas primordialmente en latín (cfr. A. Tinto, ibid.). En este fol. U6r, la grafía que pretende ser una "ç» (en las palabras «dança», "lança», "açotes», "vergüença», "grançones», "forçava», "fuerça», "dulçura», "esperança») es una "Z» al revés, lo cual es una muestra de que este tipo G.3 no se empleó para obras en castellano.

32.- Este dato rebate los postulados de M. Fernández Valladares (vid. nota 18) y otorga una baza a la tesis de Norton e Infantes, al menos para las ediciones italianas que imitan el modelo sevillano.

33.- Hasta la fecha, son cinco los ejemplares localizados de [Roma: Marcelo Silber, 15151516]: Boston-Boston Public Library (*XD.170B.9); Buenos Aires-Biblioteca Nazional Mariano Moreno (FD-214); Londres-British Library (c.20.b.15), Madrid-Biblioteca F. Zabálburu (2:249$50 \mathrm{n}^{\circ}$ 2277) y Trier-Stadtbibliothek. Weberbach (G 578: 2 an). Los ejemplares de Boston y Buenos Aires están digitalizados, respectivamente, en: $<$ https://archive.org/details/tragicomediadeca00roja/page/1>; <http://www.cervantesvirtual.com/nd/ark:/59851/bmcnc5x2>. Siguiendo los buenos consejos de la profesora Botta (cfr. nota 27), se ha procurado consultar todos los ejemplares de $J$ para asegurarnos de que CUlm era una edición independiente textualmente, y no una emisión. Sin embargo, ha sido imposible acceder al ejemplar de Madrid-Biblioteca Zabálburu, puesto que sus servicios no están disponibles al usuario en estos momentos. Sin embargo, a partir de los datos ofrecidos por C. Faulhaber («The Heredia-Zabalburu...», art. cit.), creemos que este ejemplar pertenece a la misma emisión que los otros cuatro consultados. También hemos consultado la Tesi di Laurea in Lingua e Letteratura spagnola de M. C. Armen- 


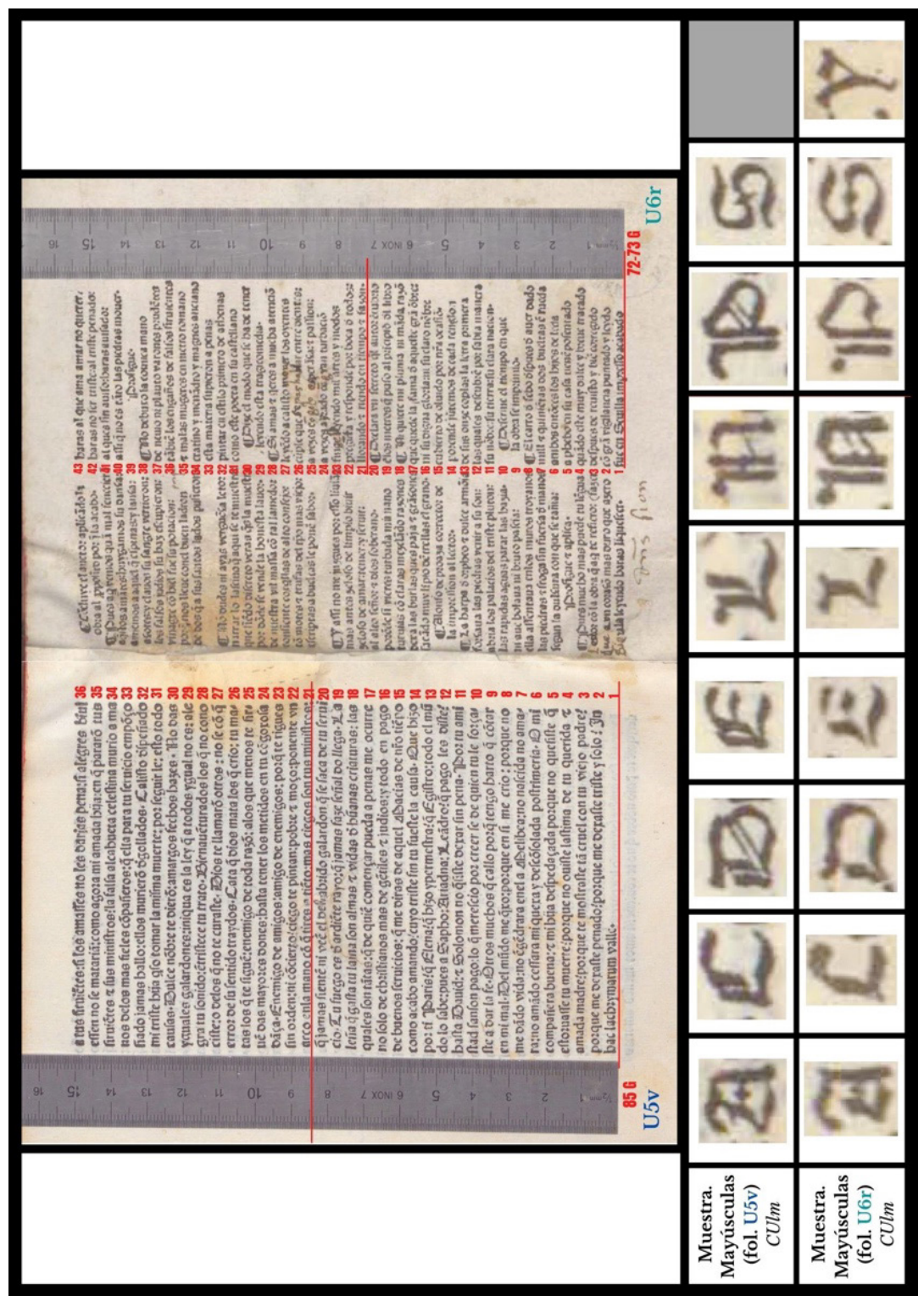

Lámina 5

ti, La tradizione primitiva de La Celestina: estudio dell'edizione Roma 1516 (J), rel. P. Botta, correl. F. J. Lobera Serrano, Roma, Università degli Studi di Roma «La Sapienza», 1995-1996. 


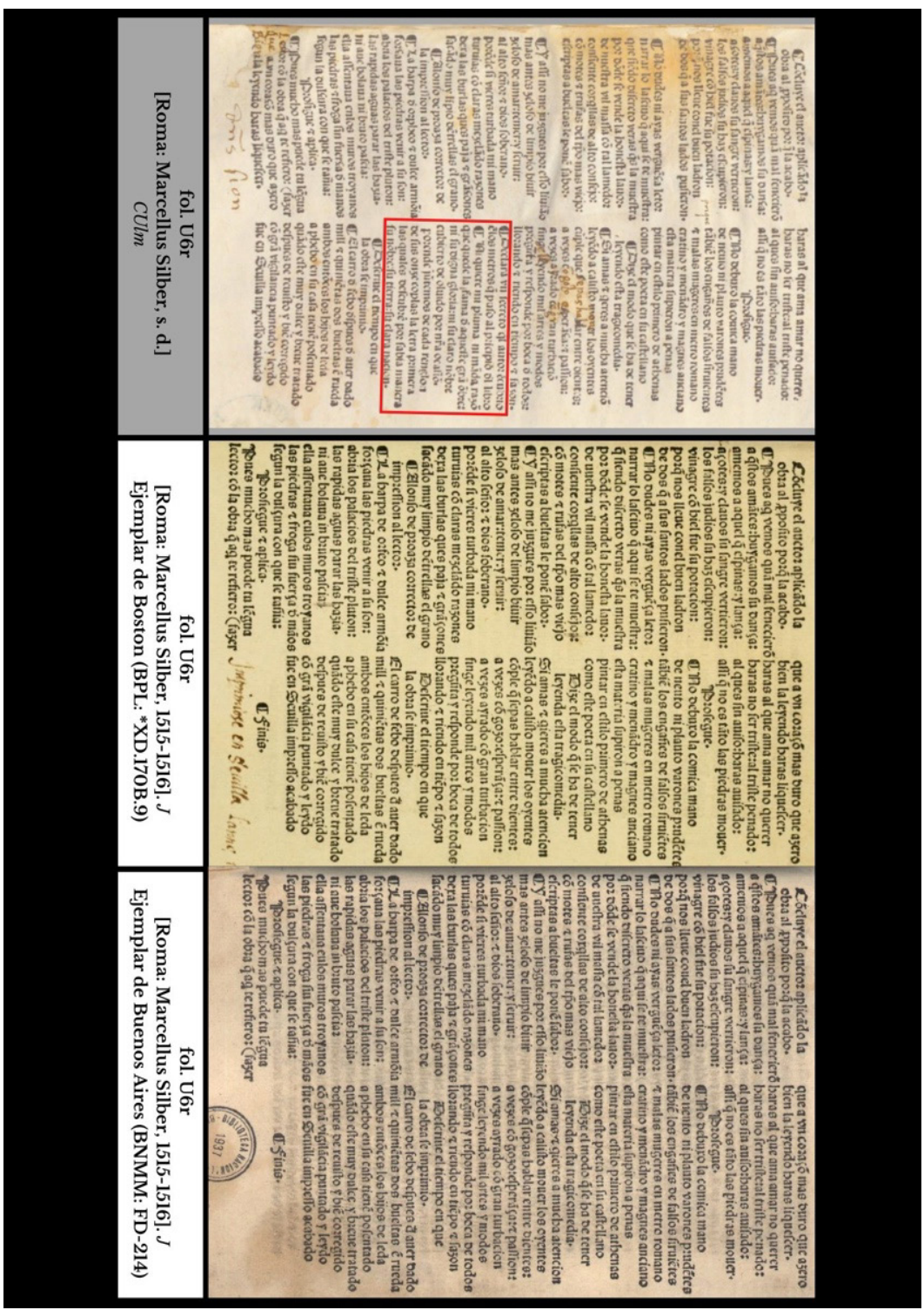

Lámina 6 
La inclusión de la quinta estrofa CUlm y su ausencia en la edición romana de [1515-1516] nos llevó a estudiar los colofones de las diferentes ediciones de la familia sevillana nacida a partir de I (Apéndice I) ${ }^{34}$. Las concomitancias de CUlm con los paratextos de $I$ al incluir las seis estrofas, la posterior desaparición de la quinta estrofa en J y Sev23 y su reincorporación en Ven31 y Ven34 anunciaban un comportamiento textual que, tras el análisis del Acto IV —uno de los más relevantes en cuestión de variantes-, confirmaban la independencia de CUlm respecto a $J$ con una serie de innovaciones que habían de afectar al resto de las ediciones de la familia sevillana-y su posición intermedia entre I y J en el stemma (Apéndice II) ${ }^{35}$.

El análisis de la tradición textual surgida a partir del primer ejemplar sevillano de la Tragicomedia (I) demuestra que CUlm es anterior a J. Sin embargo, la ecdótica debe ser respaldada - en un movimiento pendular- por la materialidad y, de este modo, siguiendo los mismos principios biblioiconográficos que Fernández Valladares concienzudamente aplicó para el caso de la edición de Juan Varela ${ }^{36}$, observamos que el taco xilográfico empleado para el acto XIV y la primera parte del acto XIX ofrece una información determinante para situar temporalmente la nueva Tragicomedia.

En él, el muro del huerto de Melibea se representa con una torre esquinera de la que sobresale una suerte de asta. Mientras que en las dos representaciones de CUlm esta aparece completa, en la edición de Roma [1515-1516] aparece ligeramente dañada. De hecho, la siguiente edición impresa en Roma en $1520(M)$ a cargo del impresor Antonio Blado, donde se emplean los mismos tacos de Silber ${ }^{37}$, también presenta el mismo deterioro que $J$ (Lámina 7; figura a). Este taco xilográfico tuvo que estropearse antes de la impresión de la edición de Silber [1515-1516], pero todavía se mantenía intacto cuando CUlm fue impresa, de modo que su estampación tuvo que ser anterior.

34.- Principalmente seguimos la más reciente actualización del stemma celestinesco de F. J. Lobera Serrano, «Un laberinto de errores»: el stemma de La Celestina», en Literatura medieval hispánica: "Libros, lecturas y reescrituras», coord. M. ${ }^{a}$ J. Lacarra, eds. N. Aranda García, A. M. Jiménez Ruiz y A. Torralba Ruberte, San Millán de la Cogolla, Cilengua, 2019, pp. 669-687.

35.- Por motivos de espacio, tanto el «Apéndice I» como el «Apéndice II» pueden consultarse en el siguiente enlace: <https://drive.google.com/drive/folders/1Obe2DjRvPIXn1zC5RkccC2HDBKeL-6L? usp=sharing $>$.

36.- M. Fernández Valladares, «Otra enigmática Tragicomedia...», art. cit., pp. 478-483.

37.- M. C. Misiti, «Alcune rare edizioni...», art. cit. 


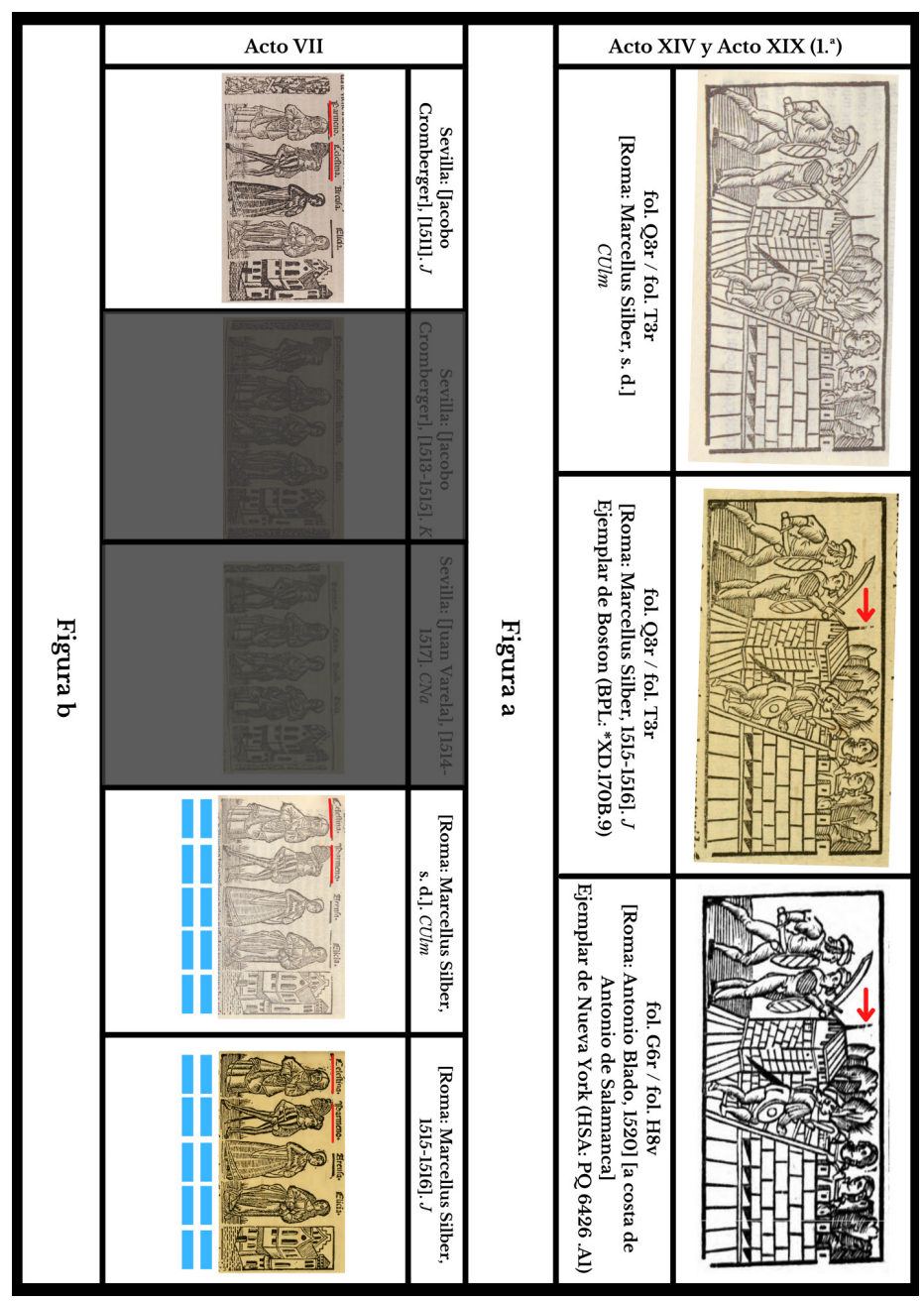

\section{Lámina 7}

Esta conjetura queda reforzada por el estudio sinóptico (Lámina 8) de las figuritas factótum de las ediciones de las primeras Tragicomedias de Toledo, Sevilla y Roma. Si fijamos como punto de referencia la edición de Sevilla impresa por Jacobo Cromberger (ca. 1511), observamos cómo CUlm sigue su misma disposición iconográfica en un altísimo porcentaje, aunque se trate de copias xilográficas. De hecho, CUlm llega a corregir algunas erratas de I como sucede en el acto VII en la falta de correlación entre las dramatis personae de Pármeno y Celestina y los grabados que los representan (Lámina 7; figura b); un error que en CUlm se resuelve en favor de la imagen. 


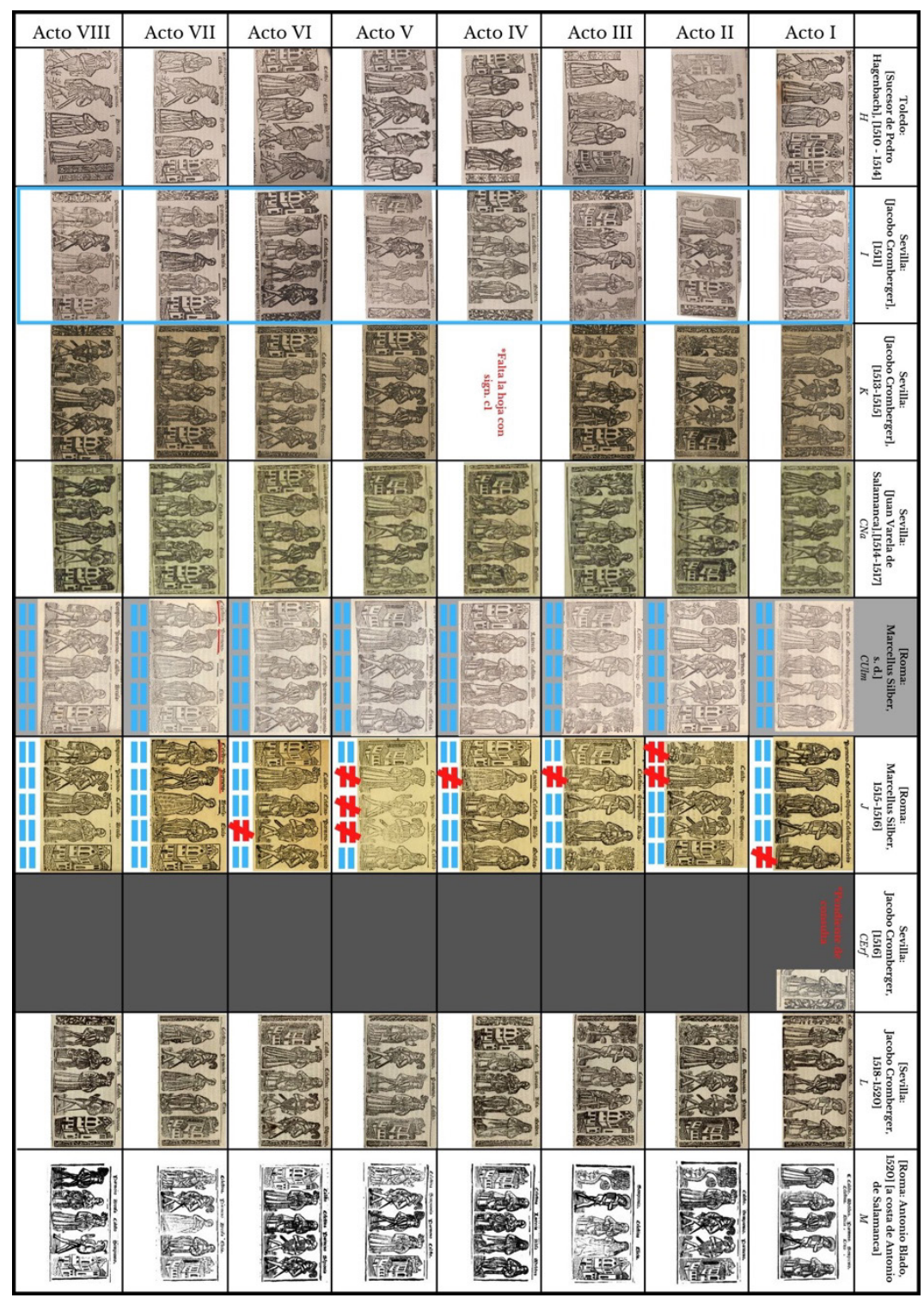




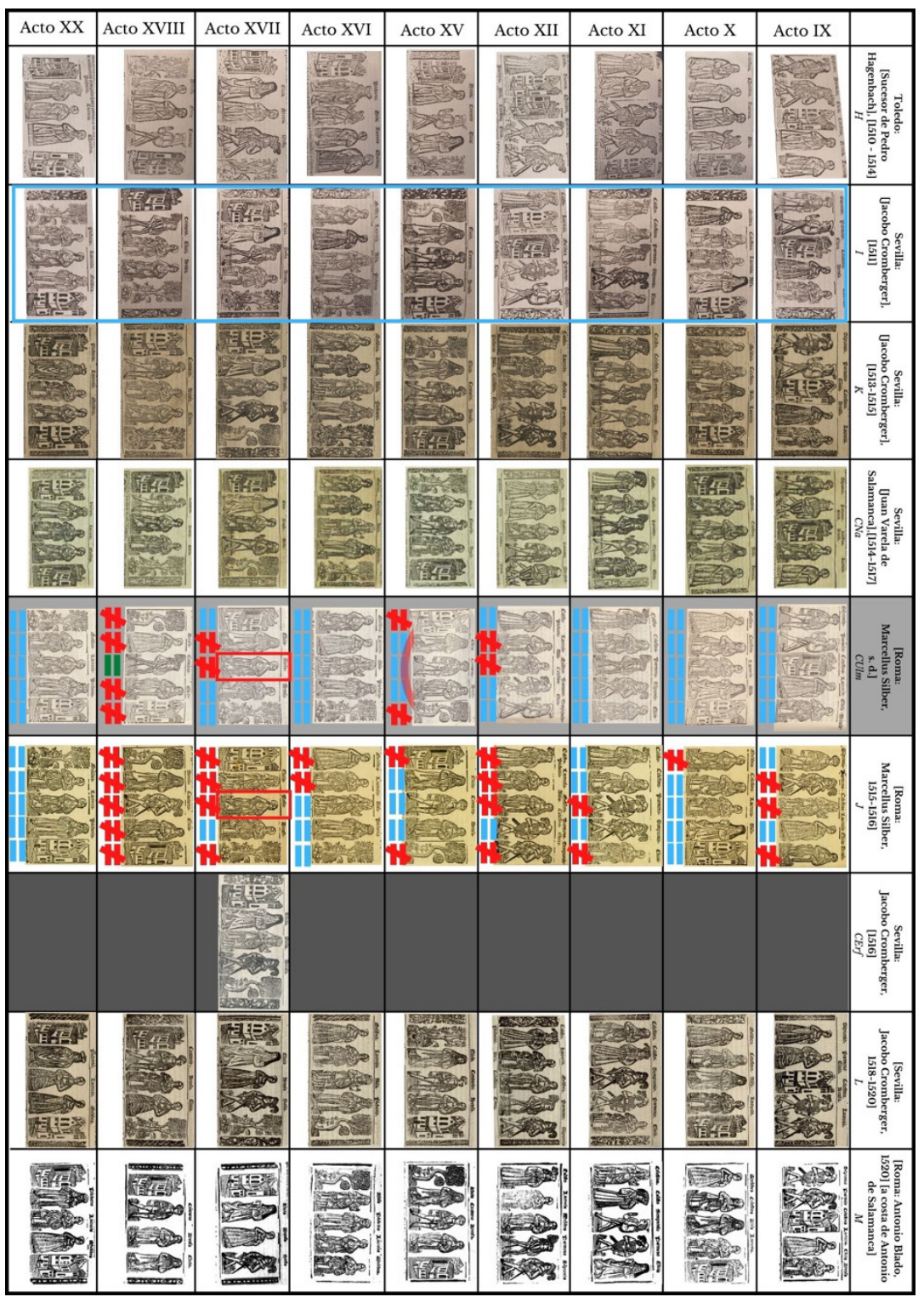

Lámina 8 
Al conocer que la actividad impresora de Marcelo Silber no fue anterior a 1510, esta nueva edición tuvo que ser impresa entre 1510 y $1515^{38}$. Incluso, su datación se podría ajustar a la horquilla temporal de [15121515], puesto que el cotejo de las figuritas factótum y la corrección de la errata en el acto VII de la edición de circa 1511 implicaría que CUlm habría sido impresa siguiendo el modelo de la primera Tragicomedia sevillana que conservamos y, por tanto, después de 1511.

Además de corroborar el innegable éxito editorial de la obra de Rojas dentro y fuera de la península ibérica y de poder añadir una nueva edición al elenco de las falsamente datadas en 1502, la relevancia de esta edición reside en que fue, con gran probabilidad, el modelo que sirvió de base de las sucesivas Tragicomedias impresas en castellano en la península itálica.

\section{Bibliografía final}

Appenzeller, B., Schoch, D. und Rosenstock, A., Catalogus Schad. Die Bibliothek des Erhard Schad (1604-1681), Ulm, Stadtbibliothek Ulm, 2013. Disponible en: <https://stadtbibliothek.ulm.de/-/media/bibliothek/ downloads/kataloge/catalogus_schad.pdf $>$.

Appunn, H. (ed.), Johann Siebmachers Wappenbuch. Die bibliophilen Taschenbücher, Harenberg, Aufl, Dortmund, 1989.

Armenti, M. C., La tradizione primitiva de La Celestina: estudio dell'edizione Roma 1516 (J), Tesi di Laurea in Lingua e Letteratura spagnola, rel. P. Botta, correl. F. J. Lobera Serrano, Roma, Università degli Studi di Roma «La Sapienza», 1995-1996.

Berger, P., Libro y lectura en la Valencia del Renacimiento, trad. Amparo Balanzá Pérez, València, Alfons el Magnànim, 1987, 2. vols.

Blanco, M. "Las piezas liminares de la Celestina: un vestíbulo enigmático", en La Célestine. Comedia o Tragicomedia de Calisto y Melibea. Actes $d u$ Colloque International, ed. F. Maurizi, Caen, Université de Caen, [1995], pp. 119-143.

Bognolo, A., "El libro español en Venecia en el siglo XVI», en Rumbos del Hispanismo en el umbral de Cincuentenario de la AIH, coord. P. Botta, Roma, Bagatto Libri, 2012, pp. 243-258. Disponible en: <https://cvc. cervantes.es/literatura/aih/pdf/17/aih_17_3_031.pdf>.

BotTA, P., (ed.), Edizione critica de La Celestina di Fernando de Rojas (atti VIII'$X X I^{\circ}$ ), Roma, La Sapienza - Università di Roma - Fac. Lettere, 2001. Disponible en: $<\mathrm{http}: / /$ rmcisadu.let.uniroma1.it/celestina/web.PDF>.

38.- Por otra parte, no deja de ser interesante observar que la signatura de la biblioteca de Schad sitúa cronológicamente este ejemplar en torno a 1515 [ca. $\neg 1515 \neg$ ]. 
BotтA, P., «Problemas filológicos de un texto impreso», Edad de Oro, XXVIII (2009), pp. 29-40. Disponible en: <http://parnaseo.uv.es/refbase/ show.php?record $=1190 \&$ submit $=$ Cite \& cite Type $=\mathrm{PDF}>$.

-, "La contaminación en N, la traducción italiana de La Celestina», Creneida, 4 (2016), pp. 107-121. Disponible en: <https://dialnet.unirioja. es/servlet/articulo?codigo $=6031629 \&$ orden $=0 \&$ info $=$ link $>$.

Branciani, D. y Falaschi, P. L., "La Biblioteca Comunale Valentiniana di Camerino", Lettere dalla Facoltà, 7.4 (2004), pp. 24- 29.

Breitenbruch, B., «Die Bibliothek des Ulmer Patriziers Erhard Schad», Ulmer Forum, 59 (1981), pp. 11-13.

CANTALAPiedra EROSTARBE, F., «Fue tanto breve quanto muy sutil. Los paratextos de La Celestina», eHumanista, 19 (2011), pp. 20-78. Disponible en: $<$ https://dialnet.unirioja.es/descarga/articulo/5674526.pdf $>$.

Cátedra, P. M. (ed.), C. Pérez Pastor, La imprenta en Medina del Campo, Valladolid, Junta de Castilla y León, 1992.

Correas, G., Vocabulario de refranes y frases proverbiales (1627), ed. L. Combet, revisada por R. James y M. Mir-Andreu, Madrid, Castalia, 2000, B334. Disponible en: <http://www.cervantesvirtual.com/descargaPdf/vocabulario-de-refranes-y-frases-proverbiales-y-otras-formulascomunes-de-la-lengua-castellana---van-anedidas-las-declaraciones-yaplicacion-adonde-parecio-ser-necesaria-al-cabo-se-ponen-las-frasesmas-llenas-y-copiosas/>.

Di CAmillo, O., "Algunas consideraciones sobre La Celestina italiana», en Rumbos del hispanismo en el umbral del Cincuentenario de la AIH, coord. P. Botta, Roma, Bagatto Libri, 2012, pp. 216-226. Disponible en: $<$ https://dialnet.unirioja.es/servlet/articulo?codigo $=7472265 \&$ \&orden $=$ $0 \&$ info $=$ link $>$.

Faulhaber, C., "The Heredia-Zabalburu Copy of the Tragicomedia de Calisto y Melibea, Sevilla, 1502 (i.e., Rome: Marcellus Silber, CA. 1516)", Celestinesca, 16.1 (1992), pp. 25-34. Disponible en: <https://ojs.uv.es/ index.php/celestinesca/article/view/19754/17527>.

Fernández Valladares, M., "Biblioiconografía y literatura popular impresa: la ilustración de los pliegos sueltos burgaleses (o de babuines y estampas celestinescas)", eHumanista. Journal of Iberian Studies, 21 (2012), pp. 87-131. Disponible en: <https://www.ehumanista.ucsb. edu/sites/secure.lsit.ucsb.edu.span.d7_eh/files/sitefiles/ehumanista/ volume $21 / 4 \% 20$ eHumanista21.fernandez.pdf $>$.

—, "Más evidencias bibliográficas para una controversia: el "colofón métrico" de la Celestina a la luz de las dos nuevas ediciones tempranas de la Tragicomedia ("Sevilla 1502")", en Controversia y producción escrita en la España Moderna, eds. M. Albisson y L. Sanz Gómez, Toulouse, Presses universitaires du Midi, 2019, pp. 215-228.DOI: https://doi. org/10.4000/criticon.8321. 
Fernández Valladares, M., "Otra enigmática Tragicomedia de Calisto y Melibea con la data contrahecha de «1502»: análisis tipográfico y ensayo de ecdótica iconográfica (con una nueva edición de la Cárcel de amor (1520)", en Literatura medieval hispánica: "Libros, lecturas y reescrituras", coord. M. ${ }^{a}$ J. Lacarra, eds. N. Aranda García, A. M. Jiménez Ruiz y A. Torralba Ruberte, San Millán de la Cogolla, Cilengua, 2019, pp. 463-501. Disponible en: <https://www.academia.edu/45183834/ Otra_enigm\%C3\%A1tica_Tragicomedia_de_Calisto_y_Melibea_con_la_data_contrahecha_de_1502_an\% C3\% A1lisis_ tipogr\%C3\%A1fico_y_ensayo_de_ecd\%C3\%B3tica iconogr\%C3\%A1fica_con_una_nueva_edici\%C3\%B3n_de_ la_C\%C3\%A1rcel_de_amor_1520>.

—, "De la tipobibliografía a la biblioiconografía: consideraciones metodológicas para un Repertorio digital de materiales iconográficos de los impresos españoles del siglo XVI", en Actas del Simposio sobre El libro en el mundo hispánico: nuevas tendencias y direcciones (Magdalen College, Oxford, 20-21 de septiembre de 2010), eds. J. C. Conde y C. Griffin, New York, Hispanic Seminary of Medieval Studies, 2020, pp. 5798. Disponible en: <https://www.academia.edu/45183608/_De_la_ tipobibliograf\%C3\%ADa_a_la_biblioiconograf\%C3\%ADa_Consideraciones_metodol\%C3\%B3gicas_para_un_Repertorio_digital_de_materiales_iconogr\%C3\%A1ficos_de_los_impresos_ espa\%C3\%B1oles_del_siglo_XVI_>.

GrifFin, C., Los Cromberger. La historia de una imprenta del siglo XVI en Sevilla y Méjico, Madrid, Ediciones de Cultura Hispánica, 1991.

—, "Celestina' s Illustrations", Bulletin of Hispanic Studies, 78.1 (2001), pp. 59-79.

HeRrIOTT, J. H., Towards a critical edition of the Celestina: a filiation of early editions, Madison [Wis.], University of Wisconsin Press, 1964.

INFANTES, V., «El laberinto cronológico y editorial de las primitivas impresiones de Celestina (1497-1514). Con una Marginalia bibliographica al cabo [y una nota final]», en La trama impresa de Celestina. Ediciones, libros y autógrafos de Fernando de Rojas, Madrid, Visor Libros, 2010; primera edición en Actas del Simposio Internacional "1502-2002: Five Hundred Years of Fernando de Rojas' 'Tragicomedia de Calisto y Melibea' (18-19 de octubre de 2002), Bloomington, Indiana University - Departamento de Español y Portugués, 2007).

Lacarra, M. ${ }^{2}$ J., "Fernando de Rojas, Celestina", en Comedic: Catálogo de obras medievales impresas en castellano hasta 1600, Zaragoza (España), ISSN 2530-1985 [en línea]. Publicación: 15-03-2019. Actualización: $31-$ 12-2020. DOI: https://doi.org/10.26754/uz_comedic/comedic_322.

-, «La tradición iconográfica de la Tragicomedia de Calisto y Melibea (Zaragoza: Pedro Bernuz y Bartolomé de Nájera, 1545», en Avatares y perspectivas del medievalismo ibérico, ed. I. Tomassetti, San Millán de la Cogo- 
1la, Cilengua, 2019, pp. 1684-1696. Disponible en: < https://www.academia.edu/45519747/La_tradici\%C3\%B3n_iconogr\%C3\%A1fica_ de_la_Tragicomedia_de_Calisto_y_Melibea_Zaragoza_Pedro_ Bernuz_y_Bartolom\%C3\%A9_de_N\%C3\%A1jera_1545_>.

LaCARRA, M. ${ }^{a}$ J., "Testimonios recuperados de La Celestina (Sevilla, 1569 y Salamanca, 1573) y de una Glosa del Cartujano a las Coplas de Manrique (Medina del Campo, 1569)», en Homenaje a Giuseppe Mazzocchi. Cauterio suave. Collana di filologia ibérica fondata da Giuseppe Mazzocchi diretta da Paolo Pintacuda, en prensa.

Lobera Serrano, F. J., «UUn laberinto de errores»: el stemma de La Celestina», en Literatura medieval hispánica: "Libros, lecturas y reescrituras", coord. M. ${ }^{\text {a }}$ J. Lacarra, eds. N. Aranda García, A. M. Jiménez Ruiz y A. Torralba Ruberte, San Millán de la Cogolla, Cilengua, 2019, pp. 669-687.

Martín Abad, J., Post-incunables ibéricos, Madrid, Ollero \& Ramos, 2011.

Misiti, M. C., "Alcune rare edizioni spagnole pubblicate a Roma da Antonio de Salamanca», en Libro antiguo español: actas del segundo Coloquio Internacional (Madrid), eds. M. L. López-Vidriero y P. M. Cátedra, Salamanca-Madrid, Universidad de Salamanca-Biblioteca Nacional de España: Sociedad Española de Historia del Libro, 1992, pp. 307-327.

NORTON, F. J., "Appendix B. The early editions of the "Celestina"», en Printing in Spain, 1501-1520, Cambridge, Cambridge University Press, 1966, pp. 141-156; "Apéndice B. Las primeras ediciones de la "Celestina"», en La imprenta en España 1501-1520, ed. J. Martín Abad (con un nuevo "Índice de Libros Impresos en España, 1501-1520»), Madrid, Ollero y Ramos, 1997, pp. 209-224.

-, A descriptive catalogue of printing in Spain and Portugal 1501-1520, Cambridge, Cambridge University, 1978.

Olivetro, G., «Ejemplares de Celestina de la Colección Foulché-Delbosc en la Biblioteca Nacional de la República Argentina», Celestinesca, 22.1 (1998), pp. 67-74. Disponible en: <https://www.jstor.org/stable/44283068>.

Pasero, C., Incunaboli ed edizioni cinquecentesche nella Biblioteca Valentiniana e comunale di Camerino, Camerino, Stab. tip. Successori Savini-Mercuri, 1933, n. CCXXXIV.

Pedraza Gracia, M. J., "La imprenta zaragozana del impresor Pedro Bernuz a través de los protocolos del notario Pedro Bernuz II», Revista Zurita, 72 (1997), pp. 29-52. Disponible en: <https://www.academia.edu/1867917/La_imprenta_zaragozana_del_impresor_Pedro_ Bernuz_a_trav\%C3\%A9s_de_los_protocolos_del_notario_Pedro_ Bernuz_II >.

-, "Los talleres de imprenta zaragozanos entre 1475 y 1577», Pliegos de Bibliofilia, 11 (2000), pp. 3-22. Disponible en: <https://www. academia.edu/2495839/Los_talleres_de_imprenta_zaragozanos_ entre_1475_y_1577>. 
Pedraza Gracia, M. J., "Por George Coci, alemán», en La literatura medieval hispánica en la imprenta (1475-1600)", eds. M. a J. Lacarra y N. Aranda, Valencia, Prensas de la Università de València, 2016, pp. 201-214.

Peeters Fontainas, J. F., L'officine espagnole de Martin Nutius à Anvers, Anvers, Societé des Bibliophiles Anversois, 1956.

Rodríguez Moñino, A., Diccionario bibliográfico de pliegos sueltos poéticos (siglo XVI), edición corregida y actualizada por A. L.-F. Askins \& V. Infantes, Madrid-Mérida, Editorial Castalia - Editora Regional de Extremadura, 1997.

RojAS, F. de (y "Antiguo Auctor»), La Celestina. Tragicomedia de Calisto y Melibea, eds. Francisco J. Lobera, Francisco Rico, Guillermo Serés et al., Barcelona, Crítica, 2000.

Saguar García, A, «¿Un programa iconográfico original? Modelos alemanes para los tacos de la edición Zaragoza, en la oficina de Jorge Coci a costa de Pedro Bernuz y Bartolomé de Nájera, 17 de junio de 1545, de Celestina", en Videoactas del I Congreso del CELPYC (4-5 de junio de 2020), eds. Enrique Fernández y Amaranta Saguar, Nueva York, CELPYC, 2020, vídeo 11. DOI: https://doi.org/10.47537/celpyc2020.11.

Timoneda, Joan de, Rosas de Romances, V. Beltran (ed.), México D. F., Frente de Afirmación Hispanista, 2018.

Tinto, A., Gli Annali Tipografici di Eucario e Marcello Silber (1501-1527), Firenze, Olschki, 1968.

Vervliet, H. D. L., Sixteenth-century printing types of the Low Countries, Leiden, Brill, 1968. 
APÉNDICE III

\section{TRAGICOMEDIA DE CALISTO Y MELIBEA \\ FERNANDO DE ROJAS (Y ANTIGUO AUTOR)}

\section{VALENCIA, JUAN JOFRÉ, 1514 (21 FEBRERO) Y}

\section{[ROMA, MARCELO SILBER, 1512-1515]}

\section{Ulm, StadtBibliotheK, SCHAD 4434}

Volumen facticio. Formato in $4 .^{\circ} .80$ hojas no foliadas. Cuadernos $\mathrm{A}^{2}$ (Valencia, Juan Jofré, 1514), B-T ${ }^{4}, \mathrm{U}^{6}$ ([Roma, Marcelo Silber, 1512-1515]). Los de cuatro hojas marcados hasta la segunda [Tij] y el de seis, hasta la tercera [Uiij].

Para Valencia, Juan Jofré, 1514: Tipografía gótica de dos tamaños. Siguiendo los códigos de Norton: (tipo 3) 138G bis (Parte título de la portada «de Calisto y Melibea [...] encerrados en sirvientes y alcahuetas»); (tipo 9) $82(-$ 83)G (Resto del texto). Caja de escritura de $174 \times 106 \mathrm{~mm}$. 42 líneas por plana. Texto impreso a línea tirada y a una columna. Título en caracteres xilográficos y tipográficos, inicial xilográfica y lombarda, grabado y orlas.

Para [Roma, Marcelo Silber, 1512-1515]: Tipografia gótica de tres tamaños. Siguiendo los códigos de Tinto: (tipo 1) 146G (Íncipit «Síguese la Comedia o Tragico-»); (tipo 4) 83-85G (Resto del texto, excepto en h. U6r); (tipo 3) 72-73G (Paratextos finales, hoja con signatura U6r). Caja de escritura de 155x94mm. 37-38 líneas; 4143 líneas en hoja con signatura U6r. Texto impreso a línea tirada y a una columna; a dos columnas en hoja con signatura U6r. Iniciales lombardas y grabados.

\section{Contenido. Valencia, Juan Jofré, 1514}

[Aj] r: Portada

[Grabado que representa a todos los personajes en diferentes escenas de la obra. Debajo, el título enmarcado por una orla formada por tres piezas xilográficas, abierta por arriba $] \mid[$ En xilografia $]$ Tragicomedia | [En tipografia: $138 G$ bis] de Califto y Melibea nueuamēnte reui $\approx$ | fta y emendada cō addicion delos argu $\mid$ mētos de cada vn auto en pzincipio. la | qual cōtiene de mas de fu agradable $\tau \mid$ dulce eftilo muchas fentēcias filofofa $\approx$ les: $\tau$ auifos muy necellarios pa māce | bos: moltrādo les los engaños $\overline{\mathrm{q}}$ eftan | encerrados en firuiētes $\tau$ alcahuetas. ||

\section{[Aj] v: Epistola:}

\footnotetext{
${ }^{1}$ Clasificación realizada a partir del orden de aparición en los actos.
}

[82-83G] • El auctoz avn fu amigo. | [Inicial xilográfica] $\left(\mathrm{S}^{4}\right)$ Uelen los $\overline{\mathrm{q}}$ de fus tierras abfentes fe hallā cōliderar : de $\overline{\mathrm{q}}$ cof aquel lugar dōde partē mayor inopia : o falta | padezca : para cōla tal puir alos Jterraneos de quien en | [...] (lín. 39) no folo avos:po a quātos lo leyerē: ofrezco los figuientes metros. $\tau \mid$ poz̄̄ conofcays dōde comieçā mis mal dolabas razones acozde $\overline{\mathrm{q}}$ to do lo $\delta 1$ antiguo autoz:fueffe fin diuifiō en vn auto: o cena inclufo ha $\mid$ fta el fegūdo auto dōde dize. Hermanos mios. zē. Vale. |

[Aij] r: Octavas acrósticas:

- El auctoz efcufando fe de fu yerro enefta $\mid$ obza q̄ efcriuio cōtra fi arguye $\tau$ compara. | [Inicial lombarda] $\mathrm{E}^{2} \mathrm{~L}$ filencio efcuda y fuele encubzir | la falta de ingenio $\tau$ tozpeza de lenguas $\mid[\ldots]$ (lin. 38) al qual jefu crifto refciba en fu glozia $\mid$ poz fu palfion fanta que a todos nos fana. $\mid$ Amonefta alos que aman que firuan a dios y de $\mid$ xen las vanas cogitacions $\tau$ vicios de amoz. ||

\section{Contenido. [Roma, Marcelo Silber, 1512-1515]}

[Bj] r: Prólogo (incompleto):

[Inicio del texto conservado] turas: poniendo rubzicas: o fumarios al pzincipio de cada acto | narrādo en bzeue lo q dentro contenia: vna cofa bien efcufada: | fegun lo que los antiguos efcriptozes vfaron:otros han litiga-| do fobze el nombre:diziendo $\overline{\mathrm{q}}$ no fe auia de llamar Comedia: | [...] (lín. 13) que cōtra mi voluntad:meter fegūda vez la pluma en tā eftraña $\mid$ labos $\tau$ tā agena de mi facultad : hurtando algunos ratos a mi $\mid$ principal eftudio con otras hozas deftinadas para recreacion: $\mid$ puefto $\overline{\mathrm{q}}$ no hā de faltar nueuos detractozes ala nueua adiciō. $\|$

[Bj] r: Texto de la Tragicomedia de Calisto y Melibea:

[146G] Sigue fe la Comedia o Tragico- | [83-85G] media de Califto $\tau$ Melibea:cōpuefta en repzehēfion $\delta$ los lo $\mid$ cos enamozados: $\bar{q}$ vencidos de fu defordenado apetito a fus $\mid$ amigas llaman $\tau$ dizen fer fu dios. Alli mifmo fecho en auifo | [...] (lin. 33) eftozuaffe tu muerte:pozque no ouifte laftima de tu querida $\tau$ amada madre:pozque te moftrafte tā cruel con tu viejo padre: | pozque me dexalte penado:pozque me dexalte trifte y folo: In haz lach 2ymarum valle· $\|$

[U6] r: Coplas de Rojas y coplas de Proaza:

[72-73G] • Cōcluye el auctoz aplicādo la $\mid$ obza al ppofito poz̄̄ la acabo $\cdot \mid$ ' Pues aq vemos quā mal fenecierō $\mid$ aq̣̂tos amātes:huygamos fu dança: |

[U6] r: Éxplicit rimado - colofón:

(Final de la segunda columna, lin. 36) • El carro $\delta$ febo $\delta$ fpues $\delta$ auer dado $\mid$ mill $\tau$ quiniètas dos bueltas è rueda $\mid$ ambos entōces los hijos de leda | a phebo en fu cafa tienē pofentado quādo efte muy dulce y breue tratado $\mid$ defpues de reuifto y biē cozregido | cō grā vigilancia puntado y leydo | fue en Seuilla impreffo acabado. \|

[80] v: [En blanco].

Grabados.

[A1] r: Grabado de portada.

[B1] v: Primer acto: conjunto de cinco figuritas factótum (Galán 1- Galán 2 - Dama 1 - Galán 3 - Vieja 1) con el nombre de los personajes que aparecen en 
tipográfica en la parte superior (Pármeno - Calisto Melibea - Sempronio - Celestina - Elicia - Crito).

[D4] v: Segundo acto: conjunto de cinco figuritas factótum (Árbol 1 - Galán 2 - Galán 4 - Galán 5 - Casa 1) con el nombre de los personajes que aparecen en tipográfica en la parte superior (Calisto - Pármeno Sempronio)

[E2] v: Tercer acto: conjunto de cinco figuritas factótum (Casa 2 - Vieja 1 - Galán 3 - Dama 1 - Árbol 2) con el nombre de los personajes que aparecen en tipográfica en la parte superior (Celestina - Sempronio Elicia).

[F1] v: Cuarto acto: conjunto de cinco figuritas factótum (Casa 1 - Dama 2 - Vieja 2 - Dama 3 - Dama 1) con el nombre de los personajes que aparecen en tipográfica en la parte superior (Lucrecia - Celestina Alisa - Melibea)

[G4] r: Quinto acto: conjunto de cinco figuritas factótum (Casa 2 - Galán 6 - Galán 4 - Galán 7 - Vieja 2) con el nombre de los personajes que aparecen en tipográfica en la parte superior (Calisto - Pármeno Sempronio - Celestina)

[H2] r: Sexto acto: conjunto de cinco figuritas factótum (Casa 1 - Galán 6 - Vieja 2 - Galán 7 - Galán 4) con el nombre de los personajes que aparecen en tipográfica en la parte superior (Calisto - Celestina Pármeno - Sempronio).

[13] r: Séptimo acto: conjunto de cinco figuritas factótum (Vieja 2 - Galán 7 - Dama 4 - Dama 1 - Casa 1) con el nombre de los personajes que aparecen en tipográfica en la parte superior (Celestina - Pármeno Areusa - Elicia).

[K4] v: Octavo acto: conjunto de cinco figuritas factótum (Galán 1 - Galán 4 - Galán 6 - Dama 5 - Casa 1) con el nombre de los personajes que aparecen en tipográfica en la parte superior (Sempronio - Pármeno Calisto - Areusa).

[L3] v: Noveno acto: conjunto de cinco figuritas factótum (Galán 1 - Galán 8 - Casa 2 - Dama 4 - Dama 5) con el nombre de los personajes que aparecen en tipográfica en la parte superior (Sempronio - Pármeno Celestina - Lucrecia - Elicia - Areusa).

[M4] v: Décimo acto: conjunto de cinco figuritas factótum (Dama 4 - Vieja 2 - Dama 5 - Dama 6 - Casa 1) con el nombre de los personajes que aparecen en tipográfica en la parte superior (Melibea - Celestina Lucrecia - Alisa).

[N4] r: Undécimo acto: conjunto de cinco figuritas factótum (Galán 6 - Vieja 2 - Galán 7 - Galán 4 - Dama 2) con el nombre de los personajes que aparecen en tipográfica en la parte superior (Calisto - Celestina Pármeno - Sempronio - Elicia).

[O2] v: Duodécimo acto: conjunto de cinco figuritas factótum (Galán 2 - Dama 1 - Dama 5 - Galán 5 - Galán 8) con el nombre de los personajes que aparecen en tipográfica en la parte superior (Calisto - Lucrecia Melibea - Pármeno - Sempronio - Pleberio - Alisa Celestina - Elicia)

[O4] v: Duodécimo acto: grabado de ancho de página (Muerte de Celestina y arresto de Sempronio y Pármeno).
[Q1] r: Decimotercer auto: grabado de ancho de página (Ejecución de Sempronio y Pármeno).

[Q3] r: Decimocuarto auto: grabado de ancho de página (Visita de Calisto al huerto de Melibea)

[R2] r: Decimoquinto auto: conjunto de cinco figuritas factótum (Casa 1 - Dama 3 - Galán 1 - Dama 1 Árbol 1) con el nombre de los personajes que aparecen en tipográfica en la parte superior (Elicia - Centurio - Areúsa).

[R4] v: Decimosexto auto: conjunto de cinco figuritas factótum (Dama 2 - Dama 4 - Vieja 3 - Anciano 1 - Árbol 2) con el nombre de los personajes que aparecen en tipográfica en la parte superior (Melibea - Lucrecia - Alisa - Pleberio).

[S2] v: Decimoséptimo auto: conjunto de cinco figuritas factótum (Casa 2 - Dama 3 - Dama 2 - Dama 5 Árbol 2) con el nombre de los personajes que aparecen en tipográfica en la parte superior (Elicia - Sofia - Areúsa).

[S4] v: Decimoctavo auto: conjunto de cinco figuritas factótum (Árbol 1 - Dama 4 - Galán 7 - Dama 1 - Casa 1) con el nombre de los personajes que aparecen en tipográfica en la parte superior (Areúsa - Centurio - Elicia).

[T3] r: Decimonono auto: grabado de ancho de página (Visita de Calisto al huerto de Melibea).

[T4] v: Decimonono auto: grabado de ancho de página (Muerte de Calisto).

[U1] r: Vigésimo auto: conjunto de cinco figuritas factótum (Árbol 2 - Dama 5 - Dama 2 - Anciano 1 - Casa 1) con el nombre de los personajes que aparecen en tipográfica en la parte superior (Melibea - Lucrecia Pleberio).

[U3] v: Vigésimo primer auto: grabado de ancho de página (Suicidio de Melibea).

\section{Orlas impresas.}

Pieza xilográfica portada inferior: $(13 \times 98 \mathrm{~mm})$

Pieza lateral izquierda: $(89 \times 7 \mathrm{~mm})$.

Pieza lateral derecha: $(91 \times 6 \mathrm{~mm})$

Iniciales:

Inicial xilográfica: $\mathrm{S}(19 \times 19 \mathrm{~mm})$ : [A1] v.

Inicial lombarda: E (9x9mm): [A2] r.

Iniciales lombardas, grupo 1 :

$\mathrm{C}(7 \times 7 \mathrm{~mm}):[\mathrm{B} 1] \mathrm{r}$.

$\mathrm{P}(7 \times 7 \mathrm{~mm}):$ [D4] r; [I3] r; [R4] v; [U3] v.

$\mathrm{H}(7 \times 7 \mathrm{~mm}):$ [D4] v.

$\mathrm{S}(7 \times 7 \mathrm{~mm}):[\mathrm{E} 2] \mathrm{v} ;[\mathrm{L} 3] \mathrm{v}$.

$\mathrm{C}(7 \times 7 \mathrm{~mm}):[\mathrm{F} 1] \mathrm{v} ;[\mathrm{I} 2] \mathrm{v} ;[\mathrm{T} 2] \mathrm{v}$.

A (7x7mm): [F2] r; [L1] r; [N4] v; [R2] r; [R4] v.

D (7x7mm): [G4] r; [N4] r; [P4] v.

$\mathrm{O}(7 \times 7 \mathrm{~mm}):[\mathrm{G} 4] \mathrm{v} ;[\mathrm{L} 4] \mathrm{v} ;[\mathrm{P} 4] \mathrm{v}$.

$\mathrm{Q}(7 \times 7 \mathrm{~mm})$ : [H2] r; [R2] r; [S4] v; [U1] v; [U3] v.

B $(7 \times 7 \mathrm{~mm}):[\mathrm{L} 4] \mathrm{r}$.

Iniciales lombardas, grupo 2 :

$\mathrm{E}(5 \times 5 \mathrm{~mm}):[\mathrm{B} 1] \mathrm{v}(\mathrm{x} 2) ;[\mathrm{H} 2] \mathrm{r} ;[\mathrm{Q} 2] \mathrm{v} ;[\mathrm{S} 2] \mathrm{r}$; $[\mathrm{S} 4] \mathrm{v}$.

$\mathrm{Q}(5 \times 5 \mathrm{~mm}):[\mathrm{E} 2] \mathrm{v}$

$\mathrm{L}(5 \times 5 \mathrm{~mm}):[\mathrm{L} 1] \mathrm{r} ;[\mathrm{O} 2] \mathrm{r}$; [U1] v.

$\mathrm{M}(5 \times 5 \mathrm{~mm}):[\mathrm{L} 4] \mathrm{r} ;[\mathrm{O} 2] \mathrm{v} ;[\mathrm{Q} 2] \mathrm{v} ;[\mathrm{S} 2] \mathrm{v} ;[\mathrm{T} 2] \mathrm{v}$

Posesión de Erhard Schard (1604-1681) cuyos fondos se encuentran en la Stadtbibliothek Ulm. 
Volumen facticio compuesto por dos hojas de la edición de Valencia (Juan Jofré, 1514, 21 de febrero), con portada (con el grabado, título — «Tragicomedia de Calisto y Melibea»-y el anuncio de «nuevamente revista y enmendada...») y parte de los preliminares (Carta del autor a un su amigo y nueve - más una parte de la décima - de las octavas acrósticas); y setenta y ocho hojas de una nueva edición desconocida identificada como [Roma: Marcello Silber, 1512-1515], con la parte final del prólogo, el texto de la Tragicomedia de Calisto y Melibea y los paratextos finales (con tres coplas de Rojas y seis de Proaza, incluyendo el éxplicit rimado).

Ejemplar bien conservado, aunque en la hoja con signatura U6r hay una mancha y algunos huecos en el texto que han sido reparados incrustando un fragmento de papel en el vuelto (U6v) y añadiendo manualmente las grafias desaparecidas. Del cuaderno A y la hoja con signatura B1 sobresalen unos flecos que contrastan con el corte superior del resto de hojas en rojo.

El vuelto de la cubierta incluye una divisa manuscrita («Buen coraçon quebranta mala ventura») y está marcado con el exlibris de su propietario consistente en una cartela ricamente adornada con volutas, vegetales y guirnaldas y en un óvalo central, blasón de la familia Schaden con el escudo (en campo de oro) con un águila explayada en sable, y sobre el casco, adornado con lambrequines, la misma águila a modo de cimera. El sello de la Stadtbibliothek Ulm aparece en la primera hoja en blanco que precede a la edición, en la parte central; en la hoja con signatura Alv, en la parte inferior izquierda — estampado dos veces por la mitad para evitar afectar al texto-; y en la hoja con signatura $\mathrm{U} 6 \mathrm{v}$, en la esquina inferior izquierda.

Anotaciones manuscritas a dos manos, en italiano (parte de la edición de Valencia) y en castellano (parte de la edición de Roma). Las primeras son la traducción directa del texto de la Tragicomedia y las segundas incluyen la dramatis personae de la obra y algunas anotaciones sueltas. Interesante marginalia en la costura del pliego añadido: « $\tau$ chi vengono nascontamente per bugi in casa della Signora»).

Bibliografia: B. Appenzeller, D. Schoch und A. Rosenstock, Catalogus Schad Die Bibliothek des Erhard Schad (16041681), Ulm, Stadtbibliothek Ulm, 2013. Disponible en: 1681), Ulm, Stadtbibliothek Ulm, 2013. Disponible
$<$ https://stadtbibliothek.ulm.de/online/die-stadtbibliothekveroeffentlicht-online>; B. Breitenbruch, «Die Bibliothek des Ulmer Patriziers Erhard Schad», Ulmer Forum, 59 (1981), pp. 11-13; F. J. Norton, A descriptive catalogue of printing in Spain and Portugal 1501-1520, Cambridge, Cambridge University, 1978, p. 419; A. Tinto, Gli Annali Tipografici di Eucario e Marcello Silber (1501-1527), Firenze, Olschki, 1968, p. 10. 